\title{
PER-MILE PREMIUMS FOR AUTO INSURANCE
}

\author{
Aaron S. Edlin \\ Working Paper 6934 \\ http://www.nber.org/papers/w6934 \\ NATIONAL BUREAU OF ECONOMIC RESEARCH \\ 1050 Massachusetts Avenue \\ Cambridge, MA 02138 \\ February 1999
}

I am grateful for the comments and assistance of George Akerlof, Severin Borenstein, Patrick Butler, Amy Finkelstein, Steve Goldman, Louis Kaplow, Todd Litman, Eric Nordman, Mark Rainey, Zmarik Shalizi, Joseph Stiglitz, Steve Sugarman, Jeroen Swinkels, Michael Whinston, Janet Yellen, Lan Zhao, several helpful people in the insurance industry, and seminar participants at Cornell, Georgetown, New York University, the University of Toronto, the University of Pennsylvania, the University of Maryland, the NBER, and the American Law and Economics Association Annual Meetings. For financial assistance, I thank the World Bank, the Olin Law and Economics Program at Georgetown University Law Center, and the UC Berkeley Committee on Research. The views expressed here are those of the author and do not reflect those of the National Bureau of Economic Research or any other organization with whom the author has been affiliated.

( 1999 by Aaron S. Edlin. All rights reserved. Short sections of text, not to exceed two paragraphs, may be quoted without explicit permission provided that full credit, including ${ }^{\circledR}$ notice, is given to the source. 
Per-Mile Premiums for Auto Insurance

Aaron S. Edlin

NBER Working Paper No. 6934

February 1999

\begin{abstract}
Americans drive 2,360,000,000,000 miles each year, far outstripping other nations. Every time a driver takes to the road, and with each mile she drives, she exposes herself and others to the risk of accident. Insurance premiums are only weakly linked to mileage, however, and have largely lump-sum characteristics. The result is too much driving and too many accidents. This paper begins by developing a model of the relationship between driving and accidents that formalizes Vickrey's [1968] central insights about the accident externalities of driving. We use this model to estimate the driving, accident, and congestion reductions that could be expected from switching to other insurance pricing systems. Under a competitive system of per-mile premiums, in which insurance companies quote risk-classified per-mile rates, we estimate that the reduction in insured accident costs net of lost driving benefits would be $\$ 9.8-\$ 12.7$ billion nationally, or $\$ 58-\$ 75$ per insured vehicle. When uninsured accident cost savings and congestion reductions are considered, the net benefits rise to $\$ 25$ - $\$ 29$ billion, exclusive of monitoring costs. The total benefits of uniform pergallon insurance charge could be $\$ 1.3-\$ 2.3$ billion less due to heterogeneity in fuel efficiency. The total benefits of "optimal" per-mile premiums in which premiums are taxed to account for accident externalities would be $\$ 32-\$ 43$ billion, or $\$ 187$ - $\$ 254$ per vehicle, exclusive of monitoring costs. One reason that insurance companies may have not switched to per-mile premiums on their own is that most of the benefits are external and the transaction costs to the company and its customers of checking odometers could exceed the $\$ 31$ per vehicle of gains that a single company could temporarily realize on its existing base of customers.
\end{abstract}

Aaron S. Edlin

549 Evans Hall

Department of Economics

UC Berkeley

Berkeley, CA 94720-3880

and NBER

edlin@econ.berkeley.edu 
...the manner in which [auto insurance] premiums are computed and paid fails miserably to bring home to the automobile user the costs he imposes in a manner that will appropriately influence his decisions.

- William Vickrey

Americans drive 2,360,000,000,000 miles each year, far outstripping other nations.' The cost of auto accidents is commensurately large: 42,000 fatalities, ${ }^{2}$ roughly $\$ 100$ billion in accident insurance, ${ }^{3}$ and according to the Urban Institute [1991] over $\$ 250$ billion in uninsured accident costs per year.

Every time a driver takes to the road, and with each mile she drives, she exposes herself and others to the risk of accident. An optimal tort and insurance system would charge people the full social cost of this risk exposure on the marginal mile of driving. Otherwise, they will drive too much and cause too many accidents. Unfortunately, neither the tort nor insurance system comes close to optimality. More unfortunate still, the cost of their shortfalls is not just too many accidents, but is compounded by the extra congestion and pollution that over driving causes.

The shortfall of the insurance system is that premiums are only weakly linked to mileage, so that they have largely lump-sum characteristics. Although premiums do depend upon statements about mileage, the mileage classifications are coarse, low-mileage discounts are extremely modest and these mileage figures are self-reported estimates of future mileage with no implicit or explicit commitment. ${ }^{4}$ Few drivers therefore pay or perceive a significant insurance cost from driving an extra mile, despite the substan-

1 See table No. 1030, Statistical Abstract of the United States, 1997, U.S. Department of Commerce. Figure for 1994.

2 See table No. 1020, Statistical Abstract of the United States, 1997. Figure for 1995.

3 After subtracting comprehensive insurance coverage, the remaining premiums for private passenger vehicles totaled \$84 billion in 1995. State Average Expenditures and Premiums for Personal Automobile Insurance in 1995, National Association of Insurance Commissioners, Jan. 1997. Commercial premiums are approximately 15 percent of premiums for private passenger vehicies. The Insurance Information Institute 1998 Fact Book, p. 22.

4 For example, State Farm distinguishes drivers based upon whether they report an estimated annual mileage of under or over 7500 miles. Drivers who estimate annual mileages of under 7500 miles receive $15 \%$ discounts (5\% in Massachusetts). The $15 \%$ discount is modest given that those who drive less than 7500 miles per year drive an average of 3600 miles compared to 13,000 miles for those who drive over 7500 per year, according to the 1994 Residential Transportation Energy Consumption Survey of the Department of Energy. The implied elasticity of accident costs with respect to miles is .05 , an order of magnitude below what the evidence suggests is the private or social elasticity of accident costs. The link between driving and premiums may be attenuated in part because there is significant noise in self-reported estimates of future mileage, estimates whose accuracy does not affect insurance pay-outs.

Insurance companies also classify based upon the distance of a commute to work. These categories are also coarse, however. State Farm, for example, classifies cars based upon whether they are used for commuting less than 20 miles per week, in between 20 and 100 miles per week, or over 100 miles per week. 
tial accident costs involved.

Drivers would pay closer to the marginal social cost of their activity if insurance companies quoted premiums at $x$ cents per-mile, where $x$ varied to reflect the per-mile risk and could depend upon territory, driver age, safety record or other relevant characteristics used today. Such per-mile premiums are advocated by Litman [1997], Butler [1990], and the National Organization for Women [1998], and are currently charged for some commercial insurance. ${ }^{5}$ Even a system of per-mile premiums would not, however, come close to the optimal accident charge.

The shortfall of the tort system is its failure to impose sufficient liability to promote efficient behavior. As a result, insurance premiums are less than the marginal accident cost of driving, whether the cost is measured as the cost of a marginal driver as it should be under a system of lump-sum premiums or as the cost of a marginal mile as it should be under per-mile premiums. The shortfall arises because a driver is not always held responsible for the damages he causes. Liability hinges on negligence, so a driver only pays for the risk he imposes on others to the extent that he is negligent and they are not. (Liability is even less frequently imposed in no-fault states). Yet as Vickrey observed, if two drivers get into an accident, even the safer driver is typically a "but for" cause of the accident in the sense that had she opted for the metro, the accident would not have occurred. ${ }^{6}$

For efficient incentives, both drivers should therefore pay the full cost of two-car accidents, regardless of negligence.' (See Green, 1976, for the general proposition.) Such a system of "double strict liability" would give both drivers the proper incentives to limit their driving and also to drive

5 For private and public livery, taxicabs, and buses, because "rates are high and because there is no risk when the car is not in operation, a system of rating has been devised on an carnings basis per $\$ 100$ of gross receipts or on a mileage basis." Bickelhaupt [1983, p. 613]. For details on per-mile commercial insurance, see "Commercial Automobile Supplementary Rating Procedures," Insurance Services Office, on file with author.

6 Sometimes, of course, only one of the drivers causes the accident such as when a driver plows into a long line of cars. If one car wasn't there to absorb the impact, another would have, so the cars that are hit do not cause the accident in any respect. Such accident substitution is not accounted for by the theoretical model we present, and reduces the externalities from driving. This substitution effect is, however, accounted for by our regression results.

7 Ignoring the incentive compatibility problem in reporting accidents, double strict liability could be implemented in a world without insurance by fining each driver for the damages she causes other drivers. If the government keeps the proceeds from fines, then each driver will bear the full accident costs, suffering her own damages and paying a fine equal to the damages of others. Accident would not, however, be reported frequently under such a system, which lead Green [1976] to dismiss the possibility of making all involved parties pay the full cost of accidents and motivated him to search for second best policies. 
carefully, incentives that account for the "Vickrey" externality of driving." The negligence system, in contrast, can make people drive safely, managing the caretaking externality, but does not induce them to drive less, managing the quantity externality (see Cooter and Ulen, 1988, and more generally Shavell, 1980).

A simple remedy for this situation-mone that avoids the accident reporting problem of double strict liability - would be to tax insurance premiums enough so that a driver pays the expected value of injuries to both herself and others. If premiums remain lump sum, such a tax would make drivers pay the full social cost of having an extra driver on the roads when considering whether to buy a car. The premium tax would also speed the day when insurance companies decide that transaction costs are low enough to justify switching to per-mile premiums, because a premium tax would increase the joint gains of the insurance company and its customers from reducing driving, accidents, and premiums. Once premiums are per-mile, the tax would ensure that drivers paid the full marginal accident cost from their driving.

Vickrey (1968), Sugarman (1993), Tobias (1993) and others have all advocated creating a closer link between driving and premiums by selling insurance with gasoline. ${ }^{9}$ The idea of charging a uniform per-gallon surcharge on gasoline to fund part or all of the compensation for auto accidents has come to be called "Pay at the Pump," and is well-surveyed in most of its variants by Wenzel [1995]. (In some variants, the surcharge would vary by territory). One virtue of these plans is that they limit or eliminate the uninsured motorist problem because gasoline can't be purchased without buying insurance. However, pay-at-the-pump plans could also limit caretaking incentives because the per-gallon fee does not vary with driving record; and, when lump sum fees are charged for bad safety records as Sugarman [1993] proposes, this limits the resulting driving reductions by lowering the marginal charge. Another fault of these plans is

\footnotetext{
8 One might worry that since such a system does not depend on fault, people would drive more carelessly as many argue they do under a system of no-fault. (See, e.g., Devlin, 1992, for some evidence that no-fault could reduce care; see Dewees, Duff, and Trebilcock [1996, pp. 22-26] for a review of the empirical literature on no-fault.) However, like a tor system, a system of double strict liability would provide optimal caretaking incentives, absent insurance, because the cost to a driver of getting into an accident is the full cost to both herself and others. She therefore receives the full benefits of caretaking to the extent that taking care reduces the frequency of accidents. If a driver were insured, under a system of double strict liability, this insurance would limit caretaking incentives in just the same way that it does under a tort system. Experience rating would, however, work to partially restore these incentives just as it does under a tort system (at the usual expense in a principal-agent framework of shifting risk back from the insurance companies to drivers).

9 Actually, Vickrey's first suggestion was that auto insurance be bundled with tires hoping that the wear on a tire would be roughly proportional to the amount it is driven. He worried about moral hazard (using a tire until it was threadbare), but concluded that this problem would be limited if refunds were issued in proportion to the amount of tread remaining.
} 
that a uniform per-gallon charge is a blunt pricing instrument to reduce the accidents from driving. Such pricing does not take account of the fact that per-gallon risk will depend upon the driver, territory, and the fuel efficiency of the vehicle (a car that gets good gasoline mileage can drive many miles on a gallon of gas). This creates an inefficiency because bad drivers in dangerous territories with fuel efficient cars will drive too much. Others may be overly discouraged from driving. ${ }^{10}$

This paper makes several contributions. First, we formalize Vickrey's insights about the externalities of driving by constructing a model relating miles driven to accidents. Second, and more important, we make state by state estimates of the total gains from switching to risk-classified permile premiums, a uniform per-gallon charge, and optimal per-mile premiums (which would include a tax to account for accident externalities). Our model allows us to account for accident externalities in these estimates and for the resulting fact that as driving falls, accident rates and hence per-mile insurance premiums will also fall.

We demonstrate that accident externalities are significant in practice by showing that states with more traffic density have considerably higher accident cost per mile driven. The more people drive on the same roads, the more dangerous driving becomes. Nationally, the insured cost of accidents is roughly four cents per-mile driven, but the marginal cost - the cost if an extra mile is driven - is much higher, roughly 7 and a half cents, because of these accident externalities. In high traffic density states like New Jersey, Hawaii, or Rhode Island, we estimate that the marginal cost is roughly 15 cents. For comparison, gasoline costs roughly six cents per-mile, so charging for accidents at the margin would dramatically increase the marginal cost of driving (though not necessarily the average cost).

A system of per-mile premiums would result in drivers paying the average - not the marginal - cost of accidents. We estimate that such a system would reduce driving nationally by $9.2 \%$, and insured accident costs by $\$ 17$ billion. After subtracting the lost driving benefits of $\$ 4.3-\$ 4.4$ billion, the net accident reductions would be $\$ 12.7$ billion or $\$ 75$ per insured vehicle. Our low estimate of net accident reductions is $\$ 9.8$ billion or $\$ 57$ per vehicle. The net savings would be $\$ 10.7-\$ 15.3$ billion if per-mile premiums were taxed optimally so that the charge accounted for driving externalities and equaled the full marginal accident cost of driving. These estimates do not account for heterogeneity in territory and drivers. Since the most dangerous drivers in the most dangerous territories would face the steepest price rise and reduce driving the most, actual benefits could be considerably larger. If state heterogeneity is a useful guide, territory heterogeneity alone would raise the benefits of either per-mile or optimal per-mile pre-

10 Sugarman [1993] counters that the per-gallon fee does rough justice, and so performs better than the current system. 
miums by $10 \%$.

A uniform gasoline tax (per-gallon premium) would not account for the heterogeneity in fuel efficiency. Taking this into account, we estimate that net accident reductions would be $\$ 8.5-\$ 10.4$ billion, roughly 20 percent less et al. our per-mile premium estimates. This figure assumes that pergallon premiums would be set sufficiently high to fund all compensation. A more typical pay at the pump plan such as Sugarman's [1993] that continues to use substantial lump sum fees would have commensurately lower benefits. Another disadvantage of per-gallon premiums- one that we do not model- is that if these premiums are not adjusted for territory, or if arbitrage limits the feasible adjustments, then the extra benefits mentioned above from tailored pricing that accounts for intrastate heterogeneity in traffic density and accident rates would not be realized.

The main reason insurance companies have not switched to per-mile premiums is probably that monitoring actual mileage with yearly odometer checks seems too costly given their potential gains, as suggested by Rea [1992] and Williamson et al. [1967, p. 247]. ${ }^{11}$ However, because of the gap in tort law pointed out above, their analysis suggests that the gains a given insurance company could realize by switching to per-mile premiums are considerably less than the social gains. If company $\mathrm{A}$ switches to per-mile premiums and its customers drive less, many of the gains will accrue to company $B$ whose customers will get into fewer accidents with A's customers. Because much of the accident reductions are external, a single company and its customers might stand to gain only $\$ 31$ per vehicle from the switch, far less than the $\$ 75$ or $\$ 91$ per vehicle of per-mile or optimal per-mile premiums. ${ }^{12}$ This discrepancy implies that the social gains from per-mile premiums might justify the monitoring costs, even if no single insurance company could profit from the change itself.

Other external benefits make the discrepancy between the private gains from per-mile premiums and the social gains even larger. As we observed, a great deal of accident costs are uninsured or underinsured. The cost of fatality risk, for example, is substantially underinsured. As with other accident costs, a substantial portion of these costs are extemal to a given insurance company and its customers. Taking into account the expected reductions in these external costs raises our estimates of the gains from per-mile premiums by $\$ 9.3-\$ 11.1$ billion. The case for policy intervention is strengthened further when nonaccident benefits such as congestion are taken into account. Congestion reductions raise our estimates of the benefits from per-mile premiums by $\$ 5.5-\$ 5.7$ billion. This brings our estimates of total national benefits from per-mile and optimal per-mile premiums to respec-

\footnotetext{
11 Monitoring costs are cited as the principal reason by actuaries I have interviewed (see also Nelson [1990] and Cardoso [1993]).

12 In a competitive industry, insurance companies cannot profit from a coordinated change, because the efficiency gains would be competed away in lower prices.
} 
tively, \$25-\$29 billion and \$32-43 billion, or \$146-\$173 and \$187-254 per insured vehicle. Benefits would be higher still, if current gasoline taxes are less than pollution costs, road maintenance costs, and other externality costs such as national security. ${ }^{13}$ The fact that accident and congestion externalities could make up more than $80 \%$ of the benefits from per-mile premiums suggests that even if monitoring costs are so large that it is rational for insurance companies to maintain the current premium structure, per-mile premiums would probably still enhance efficiency in most states once one takes account of these externalities.

Finally, the paper provides several policy ideas that could be used to change the unit of insurance from the car-year to the car-mile. A first step would be for states to reduce monitoring costs by recording odometer readings at existing safety or emissions checks and distributing the information free to insurance companies. A bolder proposal is to tax premiums to account for accident externalities. Such a tax would better align the private gains from switching to per-mile premiums with the public gains. It would also increase the total gains from switching, because the switch would lead to higher marginal charges, closer to optimal charges though still neglecting the cost of congestion and pollution. We also present a new proposal that would marry the virtues of pay-at-the-pump with per-mile premiums, by charging risk-classified per-gallon premiums metered at the pump. Such a system could make metering cheap, while making it more difficult to drive uninsured. Unlike pay at the pump, charging risk-classified premiums could address equity concems and provide caretaking incentives. It would also keep insurance agents in business so that they don't oppose reform too vocally. In fact, if these premiums are metered at the pump so that the uninsured motorist problem is limited or eliminated, then insurance agents' business will actually expand significantly. There would also be substantial incidental benefits to any individualized metering program that simple pay-at-the-pump plans can't offer: for example, pollution and road usage charges could piggyback on the system and be tailored to the model and age of each vehicle.

The remainder of this paper is organized as follows. Section 2 develops a simple model of accidents. Section 3 describes our data sources. Section 4 reviews existing evidence and arguments about the relationship between

13 These costs could easily be higher. The marginal cost per gallon of gasoline in terms of national security interest is difficult to quantify, but it is undoubtedly substantial. National defense involves many common costs, so it would be highly speculative to estimate the amount spent to defend oil interests. Nonetheless, the total amount of money the U.S. spends per year to defend U.S. interests or prepare to defend U.S. interests in oil producing countries could be comparable to current gasoline tax revenues ( $\$ 51$ billion, or 37 cents per gallon, in 1994, Statistical Abstract of the U.S., 1997, tables 478 and 1029). In the 1990s alone, the U.S. has had one war and three showdowns with Iraq.

Delucci [1997] estimates that the pollution costs of motor vehicles in terms of extra mortality and morbidity are $26.5-461.9$ billion per year in the U.S. 
miles driven and accidents and uses the model developed in Section 2 to estimate the relationship. Section 5 describes our simulations of three policy changes: per-mile premiums, optimal per-mile premiums, and uniform per-gallon premiums. Section 6 asks why we don't see per-mile premiums now and presents several policy ideas to facilitate their implementation in a cost-effective fashion.

\section{A Simple Model of Accidents and Congestion.}

We now develop a model relating driving to accidents and use it to simulate the consequences of various pricing scenarios. For simplicity, we construct an entirely symmetric model in which drivers, territory, and roads are undifferentiated and identical. The central insights continue to hold in a world where some drivers, roads, and territories are more dangerous than others, with some provisos. The relationship between aggregate accidents and aggregate miles will only hold exactly if the demand elasticity is the same across types of driving and drivers. Otherwise, accidents will be either more or less responsive to driving according to whether extra miles are driven by more or less dangerous drivers under more or less dangerous conditions.

We also limit attention to one and two vehicle accidents, ignoring the fact that many accidents only occur because of the coincidence of three or more cars. ${ }^{14}$ We treat accidents involving two or more cars as if they all involve only two cars because multi-vehicle accidents are not separated in our accident data. Refined data would increase our estimates of the benefits from the driving reductions associated with per-mile premiums because the size of accident extemalities increase with the number of cars involved in collisions.

Let

$m_{i}=$ miles traveled by driver $i$

$M=$ total vehicle miles traveled

$l=$ total lane miles

$D=$ traffic density $=M / l$

$f_{i}=$ probability that $i$ is driving at any given time

$\delta_{1}=$ damages from one-vehicle accident

$\delta_{2}=$ damages to each car in a two-vehicle accident

Holding speed constant, the fraction of the time that $i$ is driving, $f_{i}$, will be proportional to miles, $m_{i}$, so let $f_{i}=\rho m_{i}$. For convenience, imagine the $l$ lane miles are divided into $L=l z$ distinct locations. An accident

14 For example, one car may stop suddenly causing the car behind to switch lanes to avoid a collision- the accident occurs only if another car is unluckily in the adjacent lane. 
occurs between driver $i$ and $j$ if they are in the same location and neither brakes. The chance that $i$ is driving and $j$ is in the same location is $f_{i}\left(f_{j} / L\right)$. Let $q$ be the probability that neither brakes (or takes other successful evasive action) conditional upon being in the same location. The rate of damages to $i$ from two-car accidents with $j$ will then be

$$
a_{2 i, j}=\delta_{2} f_{i} \frac{f_{j}}{L} q .
$$

Summing over $j$ and substituting $\rho m$ for $f$ yields damages to $i$ from twocar accidents

Letting $c_{2} \equiv \delta_{2} \rho^{2} q / z$, we have

$$
a_{2 i}=\delta_{2} \rho^{2} m_{i} \frac{q \Sigma m_{j}}{L} .
$$

$$
a_{2 i}=c_{2} m_{i} \frac{\left(M-m_{i}\right)}{l},
$$

or, assuming $m_{i}$ is small relative to $M$,

$$
a_{2 i} \approx c_{2} m_{i} \frac{M}{l}=c_{2} m_{i} D .
$$

Ignoring multiple car accidents, the total expected accident damages suffered by driver $i$ are then

$$
a_{i}=c_{1} m_{i}+c_{2} m_{i} D
$$

The first term in the equation reflects the fact that a driver may be involved in an accident even if he is driving alone (e.g., falling asleep at night and driving into a tree), with $c_{1}$ representing the expected accident costs from driving a mile alone. The second term reflects the fact that the chance of getting into an accident with other vehicles in that mile increases as the traffic density $D$ increases. The linearity of this model in $m_{i}$ ignores the possibility that practice and experience could bring down the per-mile risk, as well as the offsetting possibility that driving experience (which is generally a safe experience) could lead to complacency and conceit.

Summing over each driver $i$ yields the total accident costs:

$$
A=c_{1} M+c_{2} M D=c_{1} M+c_{2} M^{2} / l .
$$

Observe that the cost of two-car accidents $c_{2} M^{2} / l$ increases with the square of total miles.

The marginal total accident cost from driving an extra mile is

$$
\frac{d A}{d M}=c_{1}+2 c_{2} D .
$$

In contrast, the marginal cost of accidents to driver $i$ is only

$$
\frac{d a_{i}}{d m_{i}}=c_{1}+c_{2} D
$$

The difference between these two costs, $c_{2} D$, is the externality effect. 
It represents the fact that when driver $i$ gets in an accident with another driver he is typically the "but for" cause of both drivers' damages in the sense that, but for him having been driving, the accident would not have happened. (Strangely enough, both drivers are typically the "but for" cause of all damages). This model could overstate the externality effect because of accident substitution: i.e., because if driver $A$ and $B$ collide, it is possible that driver A would have hit driver $C$ if driver B weren't there. ${ }^{15}$ Such a substitution effect would be captured in our regression estimates by a lower coefficient on traffic density, and hence a lower estimate of the externality effect.

A different view of the accident externality of driving is found by observing that the average cost of accidents per mile driven is:

$$
\frac{A}{M}=c_{1}+c_{2} D
$$

A given driver who drives the typical mile expects to experience the average damages $\frac{A}{M}$. Yet, this driver also increases $D$, which means that he also causes the accident rate for others to rise by $\frac{d D}{d \cdot M}$.

Let $c_{0}$ denote the social cost of driving a mile, exclusive of accident costs (i.e., $c_{0}$ includes gasoline, maintenance, and environmental costs). Consider $n$ identical drivers and let $V(m)$ be each person's value for driving $m$ miles $V^{\prime}>0$ and $V^{\prime \prime}<0$. Then, total driving surplus will be maximized if $m^{* *}$ is chosen to solve

$$
\max _{m} n V(m)-\left[c_{1} n m+c_{2} \frac{(n m)^{2}}{l}\right]-n c_{0} m .
$$

The first-order condition for this program is:

$$
V^{\prime}\left(m^{* *}\right)=c_{1}+2 c_{2} \frac{n m^{* *}}{l}+c_{0}
$$

In contrast, an individual who pays charge $p$ per-mile will maximize

$$
V(m)-p m
$$

choosing an $m^{*}$ so that $V^{\prime}\left(m^{*}\right)=p$.

If $p$ is set equal to $c_{0}+c_{1}+2 c_{2} \frac{n m}{l} \cdot *$, then each individual will choose $m^{*}=m^{* *}$. Accordingly, one might hope that a competitive insurance industry charging per-mile premiums would choose $p^{* *}=c_{1}+2 c_{2} \frac{n m}{l}$. However, the break-even condition for insurance is that $n p^{*} m^{*}=A\left(m^{*}\right)=$ $c_{1} n m^{*}+c_{2} \frac{n^{2} m^{* 2}}{l}$. If $m^{*}=m^{* *}$, then the per-mile premium will be $c_{2} \frac{n m}{1}$ lower than would be socially optimal, indicating that people will drive too much under per-mile premiums. Again, the discrepancy between actual premiums and efficient premiums arises because both cars in a twocar accident are the "but for" cause of the accident - if either car had

15 On the other hand, it understates the externality effect to the extent that some collisions require more than two vehicles. 
been absent, the accident would not have occurred. Efficiency therefore requires that each car pay the full cost of the accident, as Vickrey [1968] emphasized. ${ }^{16}$ This efficiency condition necessarily implies that more be collected in premiums than is required to compensate for damages. If all accidents were simple two-car accidents, then twice as much would need be collected. Competition in insurance pricing requires, in contrast, that insurance companies break even.

Fundamentally, driving causes an externality. If a person decides to go out driving instead of staying at home or using public transportation, she may end up in an accident, and some of the cost of the accident will not be borne by either her or her insurance company; some of the accident cost is borne by the other party to the accident or that party's insurance company.

\subsection{Gains from Per-mile Premiums.}

We now compare the current insurance system, which we characterize (somewhat unfairly) as involving lump sum premiums, with two altemative systems: per-mile premiums and optimal per-mile premiums. As derived above, the break-even condition for insurance companies charging per-mile premiums is

$$
p=\frac{A}{M}=c_{1}+c_{2} M / l
$$

This equation can be viewed as the supply curve for insured miles.

Let the utility of each of the $n$ drivers be quasi-linear in the consumption of non-driving goods $y$ and quadratic in miles $m$ :

$$
V(y, m)=y+a m-\frac{n}{b} m^{2} .
$$

Then, the aggregate demand will be linear:

$$
M=M_{0}-b p
$$

The equilibrium miles, $M^{*}$, and per-mile price, $p^{*}$, are found by solving these equations:

$$
\begin{gathered}
M^{*}=\frac{M_{0}-b c_{1}}{1+b c_{2} / l} \\
p^{*}=\frac{c_{1}+c_{2} M_{0} / l}{1+b c_{2} / l} .
\end{gathered}
$$

If drivers continued to drive as much under per-mile premiums as they do

\footnotetext{
16 Another way to derive our formula for accidents, in which two-vehicle accidents are proportional to the square of miles driven, is to begin with the premise that the marginal cost of a mile of driving is the expected cost of accidents to both parties that will occur during that mile.

Then the marginal cost of accidents will be twice the average: i.e., $\frac{d A_{2}-\text { car }}{d M}=2 \frac{A_{2}-\text { car }}{M}$. The unique solution to this differential equation, in which the elasticity of accidents with respect to miles is 2 , is $A_{2-c a r}=c_{2} M^{2}$.
} 
under per-year, then insurance companies would break-even by charging

$$
p=c_{1}+c_{2} M_{0} / l \text {. }
$$

However, as driving falls in reaction to this charge, the accident rate permile will also fall (because there will be fewer cars on the road with whom to collide). As the per-mile accident rate falls, premiums will fall in a competitive insurance industry, as we move down the average cost curve.

Assuming that the gas price currently reflects the environmental and road maintenance cost of driving, the social gain from charging per-mile accident premiums in this model equals the reduction in accident costs less the lost benefits from foregone driving, the shaded region in Figure 1. This surplus $S$ is given by

$$
S=\frac{1}{2}\left(\left.\frac{d A}{d M}\right|_{M_{0}}+\left.\frac{d A}{d M}\right|_{M^{*}}\right)\left(M_{0}-M^{*}\right)-\frac{1}{2} p^{*}\left(M_{0}-M^{*}\right) .
$$

By assuming quasi-linear utility, we are ignoring income effects. As a per-year premium is shifted to a per-mile charge, driving will not fall by as much as it would under a pure price change, because people don't have to pay a yearly premium and can use some of that money to purchase more driving then they would under a pure price change. These income effects are, however, overshadowed by our uncertainty about the price responsiveness of driving, so it does not seem worthwhile to consider them explicitly. We ultimately run policy simulations with elasticities of demand chosen to be below what many estimate. One reason we do so is because we should properly use a Hicksian, and not Marshallian, elasticity of demand in order to take income effects into account and calculate "exact consumer surplus."

Our benefit calculation assumes that the number of drivers would remain unchanged in a switch to per-mile premiums. In fact, the number of drivers would probably increase under a per-mile system because the total price of driving a small amount (say 2,000 miles per year) would fall. Although the extra drivers (who drive relatively little) will limit driving reductions and hence accident reductions somewhat, they would probably increase the accident savings net of lost driving benefits, and would surely do so in the case of optimal per-mile premiums. The reason is that these extra drivers gain substantial driving benefits, as evidenced by their willingness to pay insurance premiums. In the case of optimal per-mile premiums, where the premiums reflect the total accident cost of their driving, the entry of these extra drivers necessarily increases the benefits from accident cost reductions net of lost driving benefits.

One way to implement the optimal pricing scheme in this symmetric world would be to have a competitive insurance market, pricing on a permile basis, with a tax of $\left(\frac{p^{* *}}{p *}-1\right) \times 100 \%$ on premiums. This solution would work under either a fault-based tort system or a no-fault tort system, as long as every driver stands an equal chance of being at fault. If drivers 
differ in ability, then taxing premiums will work better in a no-fault system than in a tort system, however, because the optimal tax will not need to depend upon a driver's ability (i.e., upon expected share of total damages from relative negligence). To the extent that a no-fault sytem limits recovery to economic damages, as it commonly does in practice, the tax would need to be raised to account for the full externality.

\subsection{Congestion}

Congestion will fall if driving is reduced. In a fundamental respect, congestion is the counterpart to accidents. Congestion occurs when driver $i$ and $j$ would be in the same location at the same time except one or both breaks to avoid the accident. The resulting delay is, of course, costly. A rudimentary model of congestion would therefore have congestion costs rising with the square of miles, holding lane miles fixed, so that

$$
\text { congestion cost } C=a \frac{M^{2}}{l} \text {. }
$$

As with accident costs, then, the average cost of congestion per-mile equals one-half the marginal cost:

$$
\frac{C}{M}=\frac{a M}{l}=\frac{1}{2}\left(\frac{d C}{d M}\right) .
$$

Equation (8) relates the average cost of delay to the marginal cost, so that we can use estimates of the average cost of delay in order to estimate the marginal cost of delay, and in particular the extemal marginal cost of delay. Schrank, Turner and Lomax [1995] provide estimates of the average cost of delay, $\frac{C}{M}$.

Congestion cost savings that are external to the driving decision should also be added to the benefits from per-mile premiums. Assuming, that the mile foregone is a representative mile and not a mile drawn from a particularly congested or uncongested time, the person foregoing the mile will escape the average cost of delay, $\frac{C}{M}$. This savings should not be counted though among our benefits from driving reductions, because it is internalized. Viewed differently, the driver derives no net benefit from the marginal mile, because driving benefits net of congestion cost just equal operating costs. Yet, as there is less traffic on the road, other drivers will experience reduced delays and this external effect should be added to our calculations. The external effect, as with accidents, equals the difference between the marginal and average cost of delay, so the external cost of $d M$ extra miles driven is

$$
\frac{C}{M} d M \text {. }
$$

This estimate undoubtedly understates the marginal cost (and hence the external cost) of congestion substantially, because as two vehicles slow down 
they generally force others to slow down as well. A cascade of such effects becomes a traffic jam. Looking at measured flow rates of traffic as a function of the number of cars travelling suggests that during periods of congestion the marginal congestion cost of driving is often many times, up to and exceeding 10 times the average congestion experienced - at least during highly congested periods. ${ }^{17}$ To be conservative, however, we assume that the marginal cost of congestion is twice the average cost, so that the portion of the marginal cost that is external to the driving decision equals the average cost.

\section{Data.}

As a proxy for auto accident costs, we use state-level data on private passenger auto insurance premiums from the National Association of Auto Insurance Commissioners Database on Insurance Premiums for 1996. We subtract premiums paid for comprehensive coverage, so that we are left only with accident coverage. If the insurance industry is competitive, these figures represent the true economic measure of insured accident costs, which includes the administrative cost of the insurance industry and an ordinary retum on the capital of that industry. These premium data are for private passenger vehicles, so we adjust these figures to account for commercial premiums by multiplying by 1.14 , the national ratio of total premiums to noncommercial premiums. ${ }^{18}$

Insured accident costs do not come close to comprising all accident costs. As a result, our estimates of the cost of driving are too low, and correspondingly, our estimates of the benefits from the driving reductions associated with any of our policy changes are also too low. Fatalities, for example are substantially underinsured and undercompensated. Viscusi's [1993] literature review concludes that a statistical life is worth \$3-6 million, far exceeding typical auto insurance limits. ${ }^{19}$ Even if coverages were this high, liability would be limited to lost future wages, not the full value of life.

Damages are also not fully compensated for those who survive accidents. The pain and suffering of at fault drivers is not insured, and auto insurance frequently does not cover their lost wages. (In no fault states, pain and suffering is also not compensated below certain thresholds). These omitted damages are probably substantial and their inclusion would raise our estimates of the cost of driving and the benefit of driving reduction

17 Author's calculation based upon traffic flow tables. GAO, "Traffic Congestion: Trends, Measures, and Effects" GAO/PEMD-90-1, November 1989, p. 39.

18 See, p.22, the Insurance Information Institute $1998 \mathrm{Fact}$ Book.

19 The State Farm Pennsylvania ratings manual of standard coverages caps out at $\$ 500,000$. 
significantly. ${ }^{20}$ Pain and suffering is often taken to be three times the economic losses from bodily injury. Data on the miles of lanes by state come from Table HM-60, 1996 Highway Statistics, FHWA. Annual vehicle miles by state come from Table VM-2, 1996 Highway Statistics, FHWA. Data on the distribution of fuel efficiency among vehicles in the current U.S. fleet, and the distribution of miles by fuel efficiency of car come from the 1994 Residential Transportation Energy Consumption Survey. We get gasoline prices by state from the Petroleum Marketing Monthly, EIA, Table 31 ("all grades, sales to end users through retail outlets excluding taxes") and Table EN-1 (federal and state motor gasoline taxes). State level data on fatalities come from Table 100 and Table 101 of "Traffic Safety Facts 1996," U.S. Department of Transportation, Dec., 1997.

\section{Estimates of the driving-accident relationship.}

\subsection{The literature.}

Opinions differ about the relationship of driving to accidents. Patrick Butler and his collegues at the National Organization for Women have argued in editorials and insurance journals that an individual driver's accidents will be proportional to miles driven, or put differently, that the elasticity of accidents with respect to miles is 1 . Butler, Butler, and Williams (1988) point out that women drive roughly half as much as men, and have half as many accidents. Dougher and Hogarty (1994) of the American Petroleum Institute, in contrast, argue that an individual driver's accident costs will depend little, if at all, upon the amount of driving she does, and that other factors such as traffic density and type of driving are more determinative.

Credible empirical work relating driving to accidents has been limited by the scarcity of data pairing mileage and accidents. The ideal study would take such data and carefully control for the characteristics of drivers and the type of driving done in addition to mileage. Raw data (controlling for nothing) collected by the Department of Motor Vehicles in California suggests that the elasticity of an individual's accidents with respect to mileage is roughly .5 (See Massachusetts Division of Insurance, 1978, table 1). Such data would, however, understate this relationship (respectively, overstate it) if low mileage drivers were worse (respectively, better) drivers or if they tended to drive under worse (respectively, better) conditions.

The data provided by Butler, Butler and Williams [1988] on accident and annual miles differences between men and women can be used to esti-

20 In Section X, we account for fatalities separately. 4.3 
mate a model of the form:

$$
a_{s i}=c_{i} m_{s i}^{\mu}
$$

where $a_{s i}$ is the number of accidents of drivers of sex $s$ and age $i, m_{s i}$ is the number of miles driven by a driver of age $i$ and sex $s$, and $\mu$ is the elasticity of an individual's accidents with respect to miles driven. (Average accident data stratified by sex and age comes from the Penn. Department of Transportation, 1984, while annual mile data comes from the U.S. Department of Transportation, 1983.) Although Butler, Butler and Williams [1988] do not appear to estimate such a model explicitly, my regression estimates of equation (9) suggest that the elasticity of accidents with respect to miles is $\mu=.92$, close to the Butler-Butler-Williams claim and close to the value of $I$ assumed in the theoretical model. Such a regression assumes that except for the differences in their annual mileage, men and women drive equally safely and under equally safe conditions. Undoubtedly, this assumption is overly strong, but one fact stands in our favor: roughly speaking, men and women live in the same territories and territory is a critical determinant of risk.

The best controlled study of which I am aware was done by $\mathrm{Hu}$ et al. (1998), who study the effects of health status on crash rates of elderly drivers in two rural lowa counties. They control for a driver's experience and estimate elasticities of accidents with respect to miles of .35-.5 (measured at 9,000 miles per year). There are several reasons, however, to think these figures are biased downward. First, the lowa miles data must have substantial noise, as the data does not come from odometer checks but from asking the subjects how many miles they drive in a typical week. Unlike insurance company data, there is no reason for people to lie, but they may have highly uncertain estimates. Noisy data would bias the miles coefficient toward 0 (except of course to the extent that the noise is correlated with a factor related to accidents). Additionally, even a rural Iowa county is not homogeneous. People who live in or near towns may drive substantially fewer miles than those who live 20 miles from the nearest grocery store, but the miles they drive may be in more congested areas where they have more accidents per mile. Another compositional effect is that those who are good at driving may drive more (some but not all of this effect will be picked up by their health status variables). All three of these effects will tend to mute the apparent relationship between increased driving and increased accidents. This suggests that the elasticity of an individual's accidents with respect to that individual's miles could be well above .5 and perhaps even unity as our model assumes and Butler et al. argue.

The social elasticity of accidents with respect to miles of driving must substantially exceed an individual's elasticity because of the extemality effect explained in the previous section. Even if the typical individual has an elasticity of .5 , the elasticity of total accident costs with respect to total 
miles driven would be close to 1 because any individual driver will cause others to have extra accidents when he drives more. One piece of evidence on the social elasticity comes from a study of California freeways from 1960-1962 (Lundy, 1964 cited in Vickrey, 1968). A group of 32 segments of four lane freeways with low average traffic had a per-mile accident rate of 1.18 per million miles compared with 1.45 per million miles on twenty segments with more traffic. The implied incremental accident rate was 1.98 accidents per million vehicle miles, suggesting an elasticity of accidents with respect to miles of $1.7=1.98 / 1.18$. Because of the externality associated with driving pointed out in Section 1, we expect the elasticity of total accidents with respect to total miles to exceed the elasticity of an individual's accidents with respect to her driving. In fact, if an individual has elasticity of 1 as the model assumes, the "aggregate" elasticity would be 2 if all accidents involved 2 cars. The California highway data accords roughly with what one would predict given that roughly $30 \%$ of accidents involve only one vehicle. ${ }^{21}$

\subsection{Estimates of Marginal Accident Cost.}

It is worth comparing accident costs in pairs of states that have similar numbers of lane miles but very different numbers of vehicle miles traveled. For example, New Jersey and Wyoming both have approximately 75,000 lane miles. New Jersey has eight and a half times as much driving in New Jersey, however, and has an average insured accident cost of 7.7 cents per mile instead of the 1.8 cents per mile of Wyoming. Comparing Ohio and Oklahoma we see a similar pattem. Ohio has approximately two and a half times as much driving on a similar number of lane miles and has higher average accident cost ( 3.6 vs. 2.6 cents per mile). Likewise, if we compare Hawaii and Delaware, which have similar numbers of vehicle miles traveled, we find that Hawaii, which has fewer lane miles and so substantially higher traffic density, has substantially higher accident costs per-mile. In general, average accident costs are much higher in states that have a lot more driving, holding lane miles fixed. This feature, which drives the high insurance rates in dense areas, is just another view of the externality effect. The fact that marginal accident costs are higher than average accident costs is what drives up average accident costs as miles increase.

Many other idiosyncratic factors are involved, however, in a state's insurance costs. Maryland and Massachusetts, for example, have an almost identical number of lane miles and fairly similar vehicle miles traveled. However, although Massachusetts drivers only drive about 7 percent more miles per year in aggregate than Maryland drivers their average costs permile is 40 percent higher ( 6.7 cents vs. 4.8 cents), so that total insured

21 See table 27, U.S. Department of Transportation [1997]. 
accident costs are 45 percent higher. Whether this difference is attributable to differences between Massachusetts and Maryland drivers or differences between the roads or weather in the states is unknown. Cars may also be more expensive to repair in Massachusetts.

Here, we fit the model presented in Section 1 in order to form estimates of the marginal accident cost from driving an extra mile in each of the 50 states. As explained in Section 3, we use total auto accident insurance premiums paid in a state as a proxy for the total cost of automobile accidents. We estimate the effects of traffic density on accidents in two ways- by a calibration method and a regression method- as described below. The regression method utilizes the cross-state variation in traffic density to estimate its effect, while the calibration method relies upon the structure of model and data on the percentage of accidents involving multiple vehicles. Each method has weaknesses, and after discussing the likely biases in each of these methods, we conclude that the true effect of density lies somewhere between the two estimates. The traffic density effect allows us to estimate the social marginal accident cost of driving and the extent to which this cost exceeds the average, or internalized marginal, cost of driving.

We modify the model of Section 1, assuming that each state's idiosyncratic errors $\varepsilon_{\text {s }}$ enter multiplicatively as follows:

$$
\begin{aligned}
A_{s} & =\left(c_{1} M_{s}+c_{2} M_{s} D_{s}\right)\left(1+\varepsilon_{s}\right) . \\
& =c_{1 s} M_{s}+c_{2 s} M_{s} D_{s},
\end{aligned}
$$

where

$$
\begin{aligned}
& c_{1 s}=c_{1}\left(1+\varepsilon_{s}\right) \\
& c_{2 s}=c_{2}\left(1+\varepsilon_{s}\right)
\end{aligned}
$$

Once $c_{1}$ and $c_{2}$ are estimated, we can find the idiosyncratic component $\varepsilon_{s}$ for each state from the above equation using the observed values of accident costs, miles traveled and lane miles in the state. We estimate the coefficients $c_{1}$ and $c_{2}$ in two ways - one way we call a calibration model and the other a regression model.

In our calibration model, we utilize national data on the percentage of accidents involving multiple cars. Recall that national accident costs are given by

$$
A=c_{1} M+c_{2} M D \text {, }
$$

where the costs of one- and two-car accidents are, respectively,

$$
A_{1}=c_{1} M
$$

and 


$$
A_{2}=c_{2} M D
$$

Let $\bar{a}$ be the average damage per vehicle from an accident, so that twovehicle accidents have total damages of $2 \bar{a}$ and one-vehicle accidents have damages $\bar{a}$. Let $r$ denote the ratio of accidents involving two vehicles. (Nationally, $71 \%$ of crashes were multiple-vehicle crashes in 1996, and we assume that multi-car accidents involve only two cars, since we don't have data on the number of cars in multi-car accidents and since this assumption makes our benefit estimate conservative.) $)^{22}$

If $N$ is the total number of accidents in a state we have:

$$
A=N(1-r) \bar{a}+2 N r \bar{a},
$$

so that

$$
N \bar{a}=\frac{A}{1+r} .
$$

This implies that the total cost of one-car accidents is

$$
A_{1}=\frac{(1-r)}{1+r} A
$$

and similarly for two-car accidents

$$
A_{2}=\frac{2 r}{1+r} A \text {. }
$$

The one and two-car accident coefficients can then be determined from the formulas:

$$
\hat{c}_{1}=\frac{A_{1}}{M}=\frac{(1-r) A}{1+r} \frac{1}{M}
$$

and

$$
\hat{c}_{2}=\frac{A_{2}}{M^{2}} l=\frac{2 r}{1+r} A \frac{1}{M^{2}},
$$

Using the observed national data on accident costs $(A)$, miles traveled $(M)$, and lane miles $(l)$, we estimate that the one-vehicle coefficient $\hat{c}_{1}$ is roughly .7 cents per-mile, while $\hat{c_{2}}$ is $1 \times 10^{-5}$ cents per-mile squared per lane mile. This means that roughly $18 \%$ of costs are attributed to one-car accidents.

In our regression model, we estimate the coefficients $c_{1}$ and $c_{2}$ with a cross-sectional regression. Observe that equation implies that the average accident cost per-mile in state $s$ is $A_{s}=\left[c_{1}+c_{2} D_{s}\right]\left(1+\varepsilon_{s}\right)$. Assuming that the idiosyncratic components $\varepsilon_{s}$ are i.i.d. mean zero random variables that

22 The statistic $71 \%$ is found by taking the ratio of the number of multiple vehicle crashes to total crashes in table 27, U.S. Department of Transportation [1997]. This figure understates the number of accidents that involve muitiple vehicles because if a single vehicle crashes into a fixed object, for example, that is a single vehicle crash even if the vehicle swerved to avoid another car. 
are independent of $D_{s}$, OLS estimates $\hat{c_{1}}$ and $\hat{c_{2}}$ are consistent under standard regularity conditions. Table 1 gives the results of the cross-sectional OLS regression and the calibration method.

The estimate of the one-vehicle coefficient $\hat{c_{1}}$ suggests a cost of 2.2 cents per-mile. The other coefficient, $\hat{c_{2}}$, is $5.5 \times 10^{-6}$ cents per squared mile per lane mile. The regression model suggests that $55 \%$ of costs are attributable to one-car accidents, i.e., to the linear term.

In both models, the marginal accident cost is found by differentiating equation 11 which yields:

$$
\frac{d A_{s}}{d M_{s}}=c_{1 s}+2 c_{2 s} D_{s} .
$$

We find the state-specific coefficients for one and two vehicle accidents as follows:

$$
\begin{gathered}
\hat{c}_{1 s}=\hat{c}_{1}\left(1+\hat{\varepsilon}_{s}\right) \\
\hat{c}_{2 s}=\hat{c}_{2}\left(1+\hat{\varepsilon}_{s}\right) \\
\hat{\varepsilon}_{s}=\frac{A_{y}}{\hat{c}_{1} M_{s}+\hat{c}_{2} M_{s} D_{s}}-1 .
\end{gathered}
$$

Table 2 gives the marginal accident costs determined by the calibration and regression methods. Table 2 allows us to compare these costs with the average accident cost per-mile driven, which appears in column 3 . The last row models the U.S. as a whole, treating it as a single state. As we see, accounting for the Vickrey extemality appears significant regardless of which method we use, in that the marginal cost of accidents significantly exceeds the average cost. The reason is that both estimation methods put significant weight on the quadratic term. The elasticity of accidents with respect to miles (i.e. the ratio of marginal to average cost) is higher under the calibration model because that model puts more weight on the quadratic term. Below, we discuss several reasons why the regression estimates probably understate the density effect (and hence the marginal cost of driving), and why the calibration estimates overstate this effect.

The calibration method probably over states accident externalities because the theoretical model does not account for accident substitutioni.e., the possibility that if one of the drivers in a two-car accident stayed home, another accident might have substituted for the one that happened. ${ }^{23}$ A second upward bias results because in the calibration method, $c_{1}$ and $c_{2}$ are held constant, which does does not account for the fact that as driving becomes more dangerous, drivers and states both take precautionary measures. States react to higher accident rates with higher expenditures on safety by widening roads and lengthening freeway on-ramps. Drivers also

23 Though this bias could be more than offset by the fact that many accidents require the coincidence of more than two cars at the same place at the same time. Such accidents involve larger externalities than the theoretical model predicts. 
make financial expenditures, buying air bags or anti-lock brakes, and nonfinancial expenditures, by paying more attention and slowing down to avoid accidents when driving in heavy traffic. All these precautionary measures mitigate the impact of extra traffic density on accidents. At the margin, if precautions are chosen optimally so that the marginal cost of precautions equals their marginal benefit, then the envelope theorem guarantees that the calibration method would still be properly capturing the sum of accident and prevention costs (i.e., we can treat prevention as being fixed). However, to the extent that people take too little precaution at the moment, the calibration results will overstate the accident externalities. Even if precautions are currently optimal, the calibration results will overstate accident externalities for large changes in behavior, because the marginal analysis of the envelope theorem will not be applicable.

The regression method picks up both of the effects above, but unfortunately has several biases of its own that tend to make it understate the effects of density (accident externalities). Two reasons revolve around the fact that we use insurance premiums as our measure of accident costs. As mentioned at the paper's outset, a substantial portion of accident costs are not insured. If this fraction were constant across states, it would bias our calibration and regression estimates down equally. However, states with more miles driven per lane mile and higher accident costs have higher insurance premiums, and according to Smith and Wright (1992), states with higher premiums will have substantially more uninsured motorists. ${ }^{24}$ With fewer drivers insured, a smaller share of total accident costs would be insured. This effect could bias our regression estimates of marginal cost downward significantly. Another downward bias for the regression results is that as accident rates and insurance costs rise, states tend to adopt no-fault insurance reform limiting coverage of noneconomic losses so that again the percentage of costs that are insured would be lower in high-cost states.

A third source of bias, which is probably substantial, is that our measure of traffic density for a given state is a noisy measure of the traffic density where the typical mile is driven in that state because of within-state heterogeneity. In particular, adding a lot of miles of empty rural roads would not reduce the traffic density where people drive, nor the number of accidents, but would reduce the predicted number of accidents from our regression because the average traffic density would fall. This observation may explain the large positive residuals in New York, for example. Noise in our measure of traffic density would tend to lower our estimates of the accident cost of density. A final source of downward bias is that the precautionary expenditures discussed above, which are induced by high traffic density, are not included in our measure of insured accident costs.

24 In fact, they argue that there is a feedback loop so that high premiums cause more uninsured motorists and therefore higher premiums. 
To summarize, there are several reasons that the regression estimates underestimate the effect of density (and hence the marginal cost of accidents), while the calibration results overestimate the effect. The truth probably lies between these estimates, so we will treat them as framing the reasonable range of estimates.

\section{Policy simulations.}

\subsection{Methodology.}

This section estimates and compares the potential benefits of charging permile premiums, optimal per-mile premiums, and uniform per-gallon premiums. Per-mile premiums would be a linear insurance charge proportional to miles driven that allows insurance companies to break even, exactly covering accident costs. Optimal per-mile premiums would involve taxing premiums to account for the externalities of accidents. Uniform pergallon premiums would be a linear insurance charge proportional to gallons of gasoline consumed that allows insurance companies to break even. (As discussed in the introduction, most existing per-gallon proposals are more modest, covering only a portion of insurance costs.) The difference between per-mile and per-gallon premiums in our model is the variation among vehicles in fuel efficiency. This estimation paints an overly rosy picture of uniform per-gallon premiums, because it ignores the substantial heterogeneity among drivers in per-mile accident risk that a uniform pergallon premium would not account for. Such heterogeneity is manifest and substantial across regions, and may also be present among drivers in the same region, though Butler (1993) and Butler and Butler (1989) argue that miles driven is a larger determinant of bad driver experience ratings than is bad driving.

Our calculations also ignore the costs and difficulty of verifying the number of miles traveled, two issues addressed in the section on implementation. However, they do account for the cost of foregone driving benefits caused by the voluntary reduction in mileage that would result from insurance being charged by the mile or by the gallon, as opposed to the current system of by the year.

For each of these policy options-per-mile, optimal per-mile, and pergallon premiums - we estimate the consequences under three models of accident determination - linear, calibration, and regression. The linear model assumes that accidents are proportional to miles driven, i.e. that $A_{s}=$ $c_{1 s} M_{s}$. This model takes no account of the externalities from driving, nor the related fact that as people reduce their driving, accident rates per mile should fall because there are fewer drivers on the road with whom to have 
an accident. We also estimate two models--a regression model and a calibration model-that include a term that is quadratic in miles to account for the externality effect. The one and two-car accident coefficients are determined for these two models as described in the previous section.

We estimate a linear model for two reasons. First, the efficiency savings under a linear model are what a single company and its customers could expect to receive if they alone switched to per-mile pricing. Comparing the linear model with the calibration and regression modeis, therefore allows us to see how much of the accident savings are external to a given driver and his insurance company. The estimates of the linear model are also relevant if there is in fact substantial leaming-by-doing in driving that is not exhausted after the first couple of years. If driving more lowers an individual's accident rate so that they typical individual has an accident elasticity with respect to miles of $1 / 2,{ }^{25}$ then after accounting for the externality effect, the aggregate elasticity of accidents with respect to miles should be approximately one as assumed in the linear model.

Our estimates of the results of these policies naturally depend upon the price responsiveness of driving. Estimates of the price responsiveness of driving are plentiful and generally come from observed changes in the price of gasoline.

Our benchmark case assumes that the aggregate elasticity of gasoline demand with respect to the price of gasoline is .15. This figure is $25 \%$ lower than the short-run elasticity of 2 that the two comprehensive surveys by Dahl and Sterner [1991 a,b] conclude is the most plausible estimate, and also substantially lower than the miles elasticities estimated by Gallini [1983]. Goldberg [1998, p. 15] has recently made an estimate of miles elasticity near zero, though she argues that for large price changes such as those we consider here, a figure of .2 is more reasonable. ${ }^{26}$ Goldberg's standard errors are sufficiently large that her estimate is also not statistically different from .2 at the five percent level.

From the perspective of social policy, we should be interested in long run elasticities. Long run elasticities appear to be considerably larger than short run. Goodwin's [1992] survey suggests that time series studies give long run elasticities for petrol of .71 compared with .27 for the short run; cross section studies give .84 compared with .28 for the short run. Interpreting these long run elasticities in our context is problematic because in the long run, there is substantial substitution among vehicles to more fuelefficient vehicles which will be driven more miles. Still, Johansson and Shipper estimate that the long run of elasticity of miles per car with respect to fuel price is .2. Given vehicle substitution, this figure suggests that the

25 See, for example, the estimates in Hu et al. [1998] that were discussed in section 3.1 26 Miles and gas elasticity differ by the elasticity of fuel efficiency with respect to fuel price. In the short run, this elasticity is probably relatively small, though in the long run it could be substantial. 
benefits of per-mile premiums would, in the long run, be much larger than we estimate.

From our assumed fleet gas price elasticity of .15 , we compute the mileprice elasticity (which we assume is constant across vehicles) as follows. Let

$\mu_{i}=$ miles traveled by cars of fuel efficiency $i$ miles per gallon.

$e=$ the point elasticity of a given vehicle's miles with respect to marginal price per mile (assumed constant across vehicles).

$g_{i}=$ gas price per mile.

$t_{i}=$ total marginal price per mile $=4.2$ cents (maintenance) +5 cents (depreciation) + $g_{i}$ (gas price) $+p_{i}$ (insurance price $)^{27}$

$\varepsilon=.15=$ aggregate point elasticity of gasoline demand with respect to price of gasoline.

Note that since $e$ is the miles elasticity for each vehicle with respect to marginal price per mile, it is also the gasoline demand elasticity for that vehicle with respect to marginal price per mile. Then $e \frac{g_{i}}{t_{i}}$ is both the mile elasticity and gasoline elasticity with respect to the price of gasoline for a vehicle with fuel efficiency $i \mathrm{mpg}$. Since the proportion of gasoline bought by vehicles of fuel efficiency $i$ is $\left(\frac{\mu_{i} / i}{\sum_{j} \mu_{j} / j}\right)$, we can solve for $e$ using the following relationship:

$$
.15=\varepsilon=\sum_{i}\left(\frac{\mu_{i} / i}{\sum_{j} \mu_{j} / j}\right) e \frac{g_{i}}{t_{i}} .
$$

Since driving demand is linear, and each car of fuel efficiency $i$ is charged the same per-mile premium $p_{i}=p$, driving demand becomes $M=M_{0}-\sum \mu_{i 0} e \frac{p}{t_{i 0}}$ (where the subscript 0 denotes the value variables take on under current practice, with zero margiinal insurance charges). ${ }^{31}$

Solving this equation simultaneously with the per-mile premium zero profit condition (equation (5)) yields the equilibrium miles $M^{*}$ and permile premiums $p^{*}$. We first compute this equilibrium for each state. We then model the U.S. in two ways: first, in a disaggregated model where the national mile reduction is the sum of state mile reductions and second, treating the nation in an aggregated fashion as if it itself were a state. We use the equilibrium values $p_{s}^{*}, M_{s}^{*}$ to compute surplus in each state $s$ according to equation (7).

Next, we consider a per-gallon charge $\gamma$. The corresponding per-mile price for a car of fuel efficiency $i$ is $p_{i}=\gamma / i$. As we have emphasized, the per-mile price depends upon fuel efficiency under standard per-gallon proposals. Driving demand is then given by

31 For a linear demand curve $D(t)$ with a point elasticity of $e$ at price $t_{0}$, the reduction in demand from a price increase $\Delta t$ is exactly $D\left(t_{0}\right) e \frac{\Delta t}{t_{0}}$. 


$$
M=M_{0}-\sum_{i} \mu_{i 0} e \frac{\gamma}{i t_{i 0}}
$$

The break-even condition under per-gallon premiums becomes:

$$
\sum_{i} \gamma\left(\mu_{i} / i\right)=c_{1} M+c_{2} M^{2} / l, \text { where } \mu_{i}=\mu_{i 0}\left(1-e \frac{\gamma}{i t_{i 0}}\right) .
$$

Solving these two simultaneous equations in each state $s$ yields the equilibrium per-gallon charge $\gamma_{s}^{*}$ and miles $M_{s}^{*}{ }^{32}$ We can no longer use equation (7) to compute the social gain because each car type faces a different price rise $p_{i}$ under per-gallon charges. We can compute lost driving surplus from the movement along the gasoline demand curve. The percentage change in gasoline demand for a car of fuel efficiency $i$ is the same as the percentage change in miles: $e \frac{\gamma^{\circ}}{i t_{\mathrm{i} 0}}$. Since the initial gasoline demand for cars of fuel efficiency $i$ is $\mu_{i 0} / i$, the total change in aggregate gasoline demand is $\sum_{i} \mu_{i 0} \frac{e \gamma^{*}}{i^{2} t_{i 0}}$. Hence,

$$
\text { lost driving surplus }=\frac{1}{2} \gamma^{*}\left(\sum_{i} \mu_{i 0} \frac{e \gamma^{*}}{i^{2} t_{i 0}}\right) .
$$

The Harberger triangle of lost driving surplus is quite small for cars with high fuel efficiency $i$, since $i$ is squared in the denominator of the lost driving surplus expression. The vehicles do not cut their gasoline consumption much because gasoline is a small percentage of their operating expenses and so the increase in gasoline price results in a relatively small percentage increase in operating expenses.

Finally, to simulate optimal per-mile premiums, we replace the zero profit condition with the requirement that premiums equal the marginal social accident cost of driving. Thus, the "supply" equation for insured miles under optimal per-mile premiums is

$$
p=c_{1}+2 c_{2} M / l
$$

We solve this equation simultaneously with equation (??) for each state to compute the equilibrium under optimal per-mile premiums.

\subsection{Results.}

Since the consequences of all three premium options depend critically upon the price responsiveness of driving, we did sensitivity analysis by running all our nine simulations (the three policy options-per-mile, optimal permile, and per-gallon premiums--under the three models-linear, calibration, and regression) for aggregate gasoline demand elasticities of .1, .15,

\footnotetext{
32 Solving for $\gamma^{*}$ requires solving a quadratic equation, but we can ignore the root that yields negative miles.
} 
and .2. We report selected results for elasticities .1 and .2 , and report comprehensive results in Tables 3-11 for our benchmark elasticity of .15.

\subsubsection{Per-Mile Premiums}

Tables 3 and 4 present our estimates of the consequences of switching to per-mile premiums. The national reduction in vehicle miles traveled (VMT) is approximately $10 \%$ in all three models. The reduction is somewhat less in the nonlinear models because in those models, as driving is reduced, the risk of accidents also falls and with it, per-mile premiums. Since equilibrium per-mile premiums are lower in these models, the total driving reduction is lower. This effect is much more pronounced in the calibration model, because of the larger traffic density effect from two-car accidents in this model. Under the calibration models in Massachusetts, the per-mile charge falls from 6.7 cents per-mile to 5.8 cents per-mile as driving is reduced (compare Tables 2 and 3 ).

Reductions in driving would naturally be much larger in states that currently have high insurance costs and would thus face high per-mile premiums. For example, if we compare New Jersey with Wyoming (two states with similar lane miles but very different VMT's) we find that implementing per-mile premiums would reduce New Jersey's VMT by 16.2 percent under our calibration model versus 4.4 percent in Wyoming. The reduction is much larger in New Jersey because the higher traffic density there leads to higher accident rates: the per-mile premium in New Jersey would be 6.5 cents per-mile as compared to 1.8 in Wyoming.

None of the per-mile premiums have been adjusted for uninsured drivers, because data on the percentage of uninsured drivers is poor. Estimates of the percentage of uninsured drivers are often in the neighborhood of $25 \%$ (see Khazzoom [1997], Sugarman [1993], and Smith and Wright [1992]). Our estimates of the per-mile premium are calculated by dividing estimated insured accident costs by total miles driven rather than by insured miles driven. This could substantially understate the actual per-mile premiums if total miles substantially exceed insured miles. However, it wouldn't change our estimates of aggregate driving reductions significantly because even though the per-mile premium would be higher for insured miles, it would be zero for uninsured miles. ${ }^{33}$

The benefits we estimate for accident savings net of lost driving benefits are substantial in all three models. Nationally, these net accident sav-

33 Let $u$ be the fraction of uninsured drivers and $\hat{p}$ be our estimate of true per-mile premiums. If premium $\frac{\dot{p}}{1-u}$ is charged on $(1-u)$ percent of miles, then the aggregate mile reduction is identical to our estimate given linear demand. Some revenue shortfall could be expected because priced miles fall by a larger percentage than in our estimate. However, this is approximately offset by the fact that insured accident losses could be expected to fall by more than we estimate, because driving reductions would be concentrated in the insured population. 
ings range from $\$ 5$ billion to $\$ 12.6$ billion. The difference between our $\$ 5$ billion estimate under the linear model and our $\$ 12.6$ billion under the calibration model is dramatic: Accounting for accident externalities raises our estimate of benefits by 150 percent. Such a large difference makes sense. If a price change for driver $A$ causes her to drive less, much of her reduction in accident losses is offset by her lost driving benefits. In contrast, driver $B$, with whom she might have had an accident, gains outright from the reduced probability of having an accident with $A$ who is driving less. Taking this externality effect into account, nationally, the net gain is \$75 per insured vehicle under the calibration model. However, since insurance companies and their customers don't take the externality benefits into account, their view of the gain from per-mile premiums is probably closer to the $\$ 31$ of our linear model. In high traffic density states, the gain per insured vehicle is quite high - approximately $\$ 150$ in Massachusetts and New York and nearly $\$ 200$ in Hawaii and New Jersey under the calibration model.

Compare the net accident reductions in the last two rows of Table 4. Accident reductions are about 10 percent higher when the U.S. is modeled in a disaggregated way. In the national model, the U.S. is modeled as if it were a state and a uniform per-mile premium is charged in every state. This estimate therefore does not pick up one of the important benefits of determining per-mile premiums in a competitive insurance market. In a competitive insurance market, there are no cross-subsidies among territories, so high prices are charged in areas that have high accident rates, where the benefits from driving reduction will be highest. Each of our state estimates suffers from the same problem. Our benefit estimates from permile premiums are lower than they would be in competitive insurance markets, because there is substantial variation within a state in traffic density and accident rates. Areas with high accident rates will be charged higher per-mile premiums and therefore experience larger driving reductions. If within-state heterogeneity is similar to across-state heterogeneity, we could expect that our estimates of net accident gains are 10 percent lower than actual gains would be. Taking into account heterogeneity among drivers, as would happen naturally under a competitive system of per-mile premiums, would increase benefits still further.

All of our benefit estimates depend critically of course on driving elasticities. Driving reductions and net accident savings are both higher (respectively lower) if the aggregate gas demand elasticity is higher (respectively lower) than .15. The relationship between elasticity and accident savings is somewhat sub-linear, however, because the externality effect means that gains are smaller when there is less driving. Nationally, net accident benefits go from $\$ 9$ billion for an elasticity of 11 to $\$ 16$ billion for an elasticity of .2 , using the calibration model.

In general, the estimates of net accident cost savings under the regres- 
sion model are significantly smaller than under the calibration model. This difference results from the regression model putting little weight on the externality affect. As we have argued, this is probably due to several likely biases resulting from state errors being negatively correlated with traffic density. We therefore concentrate our attention on the calibration results.

Our calculation of net accident cost savings under the calibration model does not account for the possibility that reduced traffic density causes drivers to drive less carefully, or causes states to spend less money making roads safe. It is likely that as traffic diminishes, people will exercise less care, and so actual accident costs will not fall as much as we estimate. However, this effect is not necessarily a criticism of the calibration model estimates. At the margin, this observation simply implies that some of our estimated accident cost reductions will actually materialize as reductions in the cost of accident prevention. Assuming that the tort system is currently ensuring an optimal level of care, our calculation will be accurate for small reductions in driving. Some inaccuracy due to infra-marginal effects are possible, but these are probably small given that we are only considering driving reductions of $10-15 \%$.

These calculations also ignore the fact that more drivers will choose to become insured once they have the option of economizing on insurance premiums by only driving a few miles. Today, some of these low-mileage drivers are driving uninsured while others are not driving at all. To the extent that per-mile premiums (or per-gallon premiums) attract new drivers, the reduction in vehicle miles traveled will not be as large as our simulations predict. This observation does not mean that the social benefits are lower than we predict. In fact, they are probably higher. The per-year insurance system is inefficient to the extent that low-mileage drivers who would be willing to pay the true accident cost of their driving choose not to drive, because they must currently pay the accident cost of those driving many more miles. Giving them an opportunity to drive and pay by the mile creates surplus because their driving benefits exceed the cost (their benefits would always exceed the cost under optimal per-mile premiums since they are choosing to pay the cost, and benefits probably do under per-mile premiums since they pay most of the cost).

\subsubsection{Uniform Per-Gallon Premiums.}

Since we neglect driver heterogeneity, and within-state territory heterogeneity, our simulations would estimate the same benefits for per-mile premiums and per-gallon premiums if everyone drove vehicles of the same fuel efficiency. However, vehicles vary significantly in their gas mileage. Taking these composition effects into account, we find that the benefits of per-mile premiums are approximately 22 percent higher than per-gallon premiums: For $\varepsilon=.15$ national net accident savings are $\$ 10.4$ billion un- 
der per-gallon premiums compared with $\$ 12.7$ billion under per-mile premiums. This difference becomes more substantial for higher elasticities and is 28 percent when $\varepsilon=.2$.

It is not immediately obvious why per-gallon premiums perform worse than per-mile premiums. After all, both are second-best policies. The explanation, however, can be found in standard optimal tax theory. Since gasoline is a larger proportion of the operating expenses for a car with low fuel efficiency than for a car with high fuel efficiency, cars with low fuel efficiency will respond more to the price change given a similar elasticity with respect to the price of miles. The lesson from Ramsey's theory of taxation is that the burden of raising a given amount of revenue is minimized if the revenue is raised in such a way that the reduction in consumption of each good is equivalent in percentage terms. In this case, that means that each driver should reduce miles by the same percentage. That goal is not accomplished by per-gallon premiums. Per-gallon premiums result in a higher percentage of driving reduction by those who own low fuelefficiency vehicles. Hence, if per-gallon premiums and per-mile premiums raised the same amount of revenue in equilibrium (and hence had the same accident reduction), per-gallon premiums would be worse because they would entail larger lost driving benefits. The story is more complex, however, than simply the fact that per-gallon premiums tax relatively elastic goods, because the equilibrium accident reduction under per-gallon premiums is smaller than under per-mile premiums. This fact also contributes to the under performance of per-gallon premiums.

The comparison of per-gallon and per-mile premiums would naturally change if existing state and federal gasoline taxes do not take adequate account of the pollution externalities from gasoline consumption. In that case, environmental externalities would argue in favor of per-gallon premiums.

\subsubsection{Optimal Per-iMile Premiums.}

Finally, consider Tables 7 and 8 , which present our results for optimal permile premiums. Optimal per-mile premiums would involve a tax on premiums sufficiently large that a driver pays the full accident cost of his driving accounting for accident externalities. We calculate the optimal premium here under the assumption that auto insurance premiums reflect all accident costs. As we discussed in the introduction, the bulk of accident costs are not covered by auto insurance. In particular, auto insurance covers a small fraction of the value of statistical lives lost, and also doesn't covered the pain and suffering of at fault drivers. The reader should therefore keep in mind that truly optimal premium taxes would account for these costs and would be substantially higher than those used in our optimal per-mile premiums simulations. This fact makes our estimates conservative: the gains 
from these premiums and the gains from truly optimal premiums would be substantially higher than those that we calculate. ${ }^{34}$

For the linear model, the average cost of accidents $(A / M)$ equals the marginal cost $\left(\frac{d A}{d M}\right)$, so optimal per-mile premiums are the same as șecond best per-mile premiums. In our calibration and regression models, however, which take account of the accident externalities, the marginal cost of accidents exceeds the average cost. In consequence, the optimal policy is to levy a tax on premiums. Under the calibration model, optimal per-mile premiums would involve a tax of about $90 \%$ in high traffic density states such as New Jersey and about $40 \%$ in low density states like North Dakota. On average across the U.S., the premium tax would be $83 \%$ under the calibration model compared with $19 \%$ under the regression model. Because of the premium tax, driving reductions are substantially higher under optimal per-mile premiums. For the calibration model, national driving reductions are $15.7 \%$ instead of $9.2 \%$ when $\varepsilon=.15$. National net accident savings grow to $\$ 15.3$ billion from $\$ 12.7$ billion. This increase is fairly modest because of the standard feature of Harberger triangles that small price distortions (such as those under per-mile premiums) do not cause large welfare losses. However, the premium tax would collect substantial revenues: $\$ 65$ billion in the calibration model. These revenues could substitute for revenues gained from other taxation.

The optimal per-mile premium is quite large in high traffic density states. Since the marginal cost of accidents falls as driving falls, optimal premiums are particularly large when gasoline elasticity is low. For $\varepsilon=.1$, the optimal per-mile premium is approximately 12 cents in New Jersey and Hawaii. For a car that gets 20 miles to the gallon, this charge would be equivalent to more than tripling the price of gasoline in New Jersey.

\subsection{Additional Cost Savings: Congestion and Fatalities}

These policy changes would yield substantial savings in addition to the accident costs savings estimated above. In particular, congestion and fatalities will fall as driving falls. Not all of the cost savings from reduced congestion and fewer fatalities should be added to the social gain calculated above, however. Some of these costs are already internalized by drivers and reflected in the driving demand curve. Also, some of the costs of fatalities are insured and are therefore part of our measured accident cost savings. This subsection provides rough estimates of the external portion of these cost savings.

34 The fact that life insurance or other insurance serves in part to fill the compensation gap between auto insurance and full compensation does not take away from this point. 


\subsubsection{Fatalities}

Automobile insurance only covers a small portion of the monetized cost of fatalities. Responsible estimates of the cost of a "statistical life" vary widely, but tend to lie between \$1-\$10 million. ${ }^{35}$ Viscusi [1993] concludes that "the reasonable estimates of the value of life are clustered in the $\$ 3$ million-\$7 million range," and that the value should be higher when considering the general population. (The value of a statistical life is the revealed willingness to pay for a small reduction in the probability of premature fatality weighted by that probability.) Automobile insurance limits rarely exceed $\$ 500,000$, so most of the cost of fatalities is not insured by our though insurance. Since we used insurance premiums as a proxy for accident costs, our accident cost savings do not reflect the full value of lives saved. We assume that $\$ 4.5$ million is uninsured and judgment-proof, either because of bankruptcy or lack of legal liability. ${ }^{36}$ This value is chosen to be conservative, taking the middle value from Viscusi's range and subtracting $\$ 500,000$. Some portion of this value is presumably internalized, however. In particular, in deciding how many miles to drive, a rational driver already considers the cost he places on an increased chance of premature mortality. To the extent that he is judgment-proof, however, he will not consider the costs he imposes on others. In 1996, roughly 15 percent of auto accident fatalities, or 6,300 , were to non-occupants, largely bicyclists and pedestrians. ${ }^{37}$ Roughly $41 \%$ of fatalities $(17,500)$ were from collisions with another motor vehicle in transport. ${ }^{38}$ Since from any driver's perspective at least $1 / 2$ of the fatalities he expects from multi-vehicle accidents will be in other vehicles, summing these figures suggests that $36 \%$ of the 42,000 auto fatalities in 1996 were external to the driving decision. This methodology understates the externalities considerably, since in many cases, a car will overturn or collide with some fixed object to avoid hitting another vehicle.

Under the assumption that as driving falls, fatalities fall in proportion to accidents, Table 10 gives the monetized value of statistical lives saved that are uncompensated by insurance and are external to the driving decision. This value is a benefit of per-mile premiums in addition to the net reduction in insured accident costs estimated in Section 4.2. Under our calibration model, the $10 \%$ national driving reduction would lead to approximately 6600 fewer fatalities for $\varepsilon=.15$. Under the assumptions discussed above, we should therefore add about $\$ 11$ billion $\approx 6600 \times .36 \times \$ 4.5$ million to the benefits calculated in the previous section to account for fatalities. Note

\footnotetext{
See Viscusi (1993) and Fisher et al. (1989).

36 In comparison, the Urban Institute study [1991] used a figure of $\$ 2.4$ billion per life in 1988 dollars.

37 Table 53, U.S. Department of Transportation [1997].

38 Table 66, U.S. Department of Transportation [1997].
} 
that the benefits under optimal per-mile premiums would be even higher if the optimal premium included a payment to account for external fatalities, rather than just being the optimal charge to account for external accident costs.

Life insurance and other non-auto insurance policies do, of course, helped to fill the compensation gap between auto insurance coverage and the full value of life, but this fact does not affect the accuracy of the estimates above. When one person's driving saves the life of a pedestrian, bicyclist, or another driver, the cost savings does not disappear merely because that person's life was insured. Such insurance only shifts the cost to the insurance company. The $\$ 500,000$ in assumed compensation from auto insurance was subtracted from our value of life to avoid double counting because the savings was already counted in the previous section as a reduction in the insured cost of accidents. Since fatality costs insured by non-auto insurance was excluded from the previous section, it should properly be included in this calculation.

\subsubsection{Congestion}

Some portion of congestion cost savings should also be added to the benefits from per-mile premiums. These costs are large and a growing concern. ${ }^{39}$ A detailed study by Schrank, Tumer and Lomax [1995] estimates that the cost of congestion from delay and increased fuel consumption in the U.S. exceeded \$49 billion in 1992 and $\$ 31$ billion in $1987 .^{40}$ This study valued time at $\$ 8.50 / \mathrm{hr}$. in 1987 and $\$ 10.50 / \mathrm{hr}$. in 1992 , which will seem a considerable undercounting to those who, like myself, would far prefer to be at work than stuck in a traffic jam. If we project this figure to $\$ 60$ billion in 1995, this amounts to 2.5 cents for every mile driven. As discussed in presenting our model, although the marginal cost of congestion is many times the average cost of congestion during congested periods, we conservatively assume that the marginal cost of congestion is twice the average cost, so that the external marginal cost of congestion equals the average. Table 9 gives our estimates of the national portion of congestion reduction that is external and should be added to net accident benefits and fatality reductions for $\varepsilon=.15$. In all models, estimated externalized gains from congestion reductions are large, ranging from $\$ 4.2$ billion to $\$ 9.4$ billion. Under per-mile premiums, congestion reductions are largest in the regression and linear models because in those models, accident rates (and hence per-mile premiums) don't fall much or at all as driving falls. In contrast,

39 A recent poll by Mark Baldarassare shows that voters in California are "most satisfied with their jobs" and "most negative about traffic." New York Times 6/2/98, A1, "Economy Fades As Big Issue in Newly Surging California."

40 My summation for the 50 urban areas they studied. See Table A-9, p. 13, and Table A-15, p. 19, in Shrank, Tumer and Lomax [1995]. See also Alt +fst [1997], who estimates congestion costs at $\$ 22.5-99.3$ billion. 
the congestion reductions for optimal per-mile premiums are largest $(\$ 9.4$ billion) under the calibration model, because of the large premium tax that accounts for accident externalities from driving. Congestion reductions are smallest under per-gallon premiums because this policy yields the smallest driving reduction of the three, as discussed above.

These calculations are based upon the average cost of delay. Congestion delays, of course, are concentrated during certain peak time periods and at certain locations. This fact simply means that the congestion reductions from per-mile pricing are concentrated during these time periods and these locations. Our calculations are robust provided that the elasticities of demand for congested miles and non-congested miles are comparable, and that the externalized marginal cost is a constant multiple of average cost. ${ }^{41}$ The concentration of congestion costs simply suggest that we would be even better off if driving were priced particularly high during congested periods and somewhat lower otherwise.

\subsection{Total Benefits.}

Table 11 gives total estimated annual national benefits from per-mile, pergallon, and optimal per-mile premiums for $\varepsilon=.15$. The total benefits are expressed both in aggregate and per insured vehicle. These annual benefits are quite high and using the regression estimates as our lower bound and the calibration estimates as our upper bound suggests that charging by the mile would be socially beneficial if verifying miles could be achieved for less than $\$ 146-\$ 173$ per car each year. Note that external benefits made up $\$ 20-\$ 24$ billion of our estimated benefits since net accident savings were only $\$ 5$ billion under the linear model. The gains under optimal per-mile premiums were higher still at \$187-\$254 per vehicle. These estimates neglect environmental gains that would result if the current price of gasoline does not adequately account for emissions, noise pollution and road maintenance. Our estimates also did not account for underinsured and uninsured accident costs to those who survive accidents. Including these latter figures into our estimates of eliminated accident extemalities would raise the estimated benefits by several billion dollars more.

The total benefits are quite large even for the linear model where acci-

41 To understand why, consider a model with two types of miles: $A, B$. Let the initial quantities of driving these miles be $a, b$, and let $C_{a}, C_{b}$ be the total cost of delay during driving of types $A, B$ respectively. Then, the average cost of delay is $c=\frac{C_{n}+C_{b}}{a+b}$, and the average cost of delay during driving of the two types is $c_{a}=C_{a} / a, c_{b}=C_{b} / b$. The externalized marginal congestion costs are likewise $c_{a}, c_{b}$. Observe that if a uniform per mile price $p$ is charged for both types of miles, the congestion savings will be $\frac{p e}{g}\left[a c_{a}+b c_{b}\right]=$ pe $\left(C_{a}+C_{b}\right)$, where $g$ is the initial gas cost per mile of driving, and $\varepsilon$ is the elasticity of miles with respect to the price of gasoline. This is equivalent to what we would calculate if we treated the two types of miles equivalently, with $c$ as the externalized marginal cost of miles. Then we would estimate the congestion reduction as: $\frac{p e}{g}[a+b] c=\frac{p c}{g}\left(C_{a}+C_{b}\right)$. 
dents are proportional to mileage. Under the linear model, the total benefits of per-mile premiums are $\$ 107$ per vehicle, and the benefits of per-gallon premiums are $\$ 88$ per vehicle. This model would be roughly accurate if individual elasticities of accidents with respect to miles were .5 , because then the externality effect would make the social elasticity roughly one, as in a linear model. Estimates under the regression model lie roughly halfway in between the linear model and the calibration model.

\section{Implementation.}

This section begins by asking the economist's standard question: If permile premiums are so great, why don't we see them already? After discussing the likely reasons for their absence, we argue that the fact that insurance premiums are now only weakly tied to actual miles driven. Finally, we discuss several options for facilitating or implementing per-mile premiums.

\subsection{Why don't we see per-mile premiums now?}

Standard contracting analysis predicts that an insurance company and its customers would not strike a deal with a lump sum premium if accident costs increase with miles, and if miles are observable. In that case, as Rea [1992] has pointed out, the insurance company could charge for insurance by the mile and make more money while leaving its customers as well off or better off. (If the insurance company is a mutual company it could give this excess back to policyholders.) There are several reasons, however, why this price restructuring may not be or may not appear to be a Pareto improvement to the customer and his insurance company. We discuss these reasons below.

Monitoring costs. As Rea points out, checking odometers is costly, and the gains to the insurance company and its customers from more efficient pricing may be less than the cost to the customer and the insurance company than of bringing a car to a certified odometer checker every year. However, as this paper has emphasized, many of the gains from the customer driving less will be realized by other drivers and other insurance companies, because there will be fewer accidents, less congestion, and less pollution. Our estimates suggest that these external effects are large and could justify per-mile premiums, even in cases where insurance companies and their customers would not want to choose per-mile premiums on their own. Additionally, it may be much cheaper to monitor miles if all insurance carriers charge for insurance by the mile, as we argue below.

Low elasticities. Driving might also be less price sensitive than our estimates assume. Some in the insurance industry have argued that drivers 
will not respond to price changes and therefore criticize per-mile premiums (see Nelson [1990]). Certainly, there is no guarantee that drivers will be as responsive to price changes as we assume. However, our assumed price elasticities lie in the middle range of existing estimates, and the truth could be either higher or lower. The possibility that price elasticities could be lower is therefore a poor justification for current pricing.

Adverse selection. Adverse selection is another reason that a given insurance company may not want to switch to per-mile premiums on its own. Even if the insurance company knows the average miles driven per year by drivers in a given risk pool, it does not (currently) know the miles that given individuals drive. If it charges a per-mile premium equal to the current yearly premium for the pool divided by the average number of miles driven by drivers in the pool, it will lose money. Those who drive more miles than the average will leave the pool for a firm charging per-year rates and those who drive less miles will stay with this insurance company. However, low mileage drivers in any given per-year risk class with a given accident experience level will tend to be worse drivers than high mileage drivers in the same risk class. (Accident costs divided by miles driven would be a sensible measure of per-mile risk.) This adverse selection means that the insurance company will have to charge a fairly high per-mile price to break even given the selection problem and the possibility that high-mileage drivers can choose to pay fixed annual premiums with other insurance companies. In principle, the insurance company could probably find a sufficiently high per-mile price that would increase profits. However, one could understand the hesitancy of a marketing director to propose to the CEO that the insurance company change its pricing structure in a way that would make its prices less attractive than other insurance companies' to a large percentage of its current customers. The CEO would probably balk, even if the finest economic consultants argued that the plan should increase profits.

Risk aversion. Customers may not know exactly how many miles they will drive in a year, and so there is an insurance motive to continue charging them a fixed yearly price. However, we don't see gasoline clubs that sell a year's worth of gasoline for a fixed price, nor vacation clubs that sell a year's worth of airplane travel for a fixed price. The moral hazard problem is simply too large.

Odometer fraud. If premiums are based upon odometer readings, the first thought to spring to any economist's mind will be that people will tamper with their odometers to reduce insurance premiums. Perhaps surprisingly, insurance industry advocates do not bring up this possibility when they write in opposition to the idea of charging by the mile. While odometer tampering is certainly a concem, it is probably not a huge problem. Tampering with an odometer is already a crime, and this simple fact will be enough to stop most people from tampering. Additionally, tampering 
with an odometer is not trivial and most people will not be able to do this on their own. Currently, there are substantial incentives to set odometers back to sell used cars. The odometer fraud unit within the Department of Transportation believes, however, that such tampering generally does not occur when individuals sell their cars (despite the fact that they could make several thousand dollars by tampering), and is generally restricted to the wholesale car trade. Today, there is apparently no retail market for setting back odometers, despite large incentives when selling a used car. ${ }^{42}$ Some combination of the penalties from violating the law (real or of conscience) together with the difficulty of adjusting odometers appears to be sufficient at present to deter most tampering. Penalties could be adjusted upward somewhat to compensate for the increased incentive to tamper resulting from insurance premiums being based upon miles.

Prospective nature of insurance. A final reason that some insurance executives have given to explain why they don't charge per-mile premiums is that insurance charges are prospective in nature. They don't want to collect ex post surcharges from drivers who drive a lot, particularly if the driver had no accident. This problem, however, could be surmounted easily if the charge were guaranteed in advance by a credit card company.

\subsection{Policy Ideas for Implementing Per-mile Premiums.}

This section presents several policy ideas that address the practical and political problems involved in switching to a per-mile premium regime.

The first thing the govemment could do to facilitate the adoption of per-mile premiums would be to reduce the cost of monitoring miles, which is probably the principal reason, other than inertia, that per-mile premiums are not currently charged. The simplest thing to do in states such as Massachusetts that already have regular checks of automobiles for safety or emissions, would be to record odometer readings at these checks and transfer this information together with vehicle identification numbers to insurance companies. This would remove the need for a special trip and special stations for odometer checking. Even in states that do not have any safety or emissions checks, there would be substantial economies of density in checking odometers simply because the time required to travel to the nearest odometer checking station would be much smaller if all insurance companies switched to per-mile premiums at once than if a single company did.

Another way to encourage insurance companies to switch to per-mile premiums would be to transfer some of the externality gains to them. For example, since per-mile premiums would help states meet the standards of the Clean Air Act, states or localities could provide financial incentives to

42 Setting back an odometer 40,000 miles could increase the sale price of most cars by $\$ 2,000-\$ 4,000$. 
insurance companies that switched (e.g., tax credits or valuable pollution permits). Money might also justifiably be used from the Highway Trust Fund, since with less driving, fewer roads are needed.

An interesting possibility proposed in March 1998 by the National Organization for Women is to require insurance carriers to offer customers a choice between per-mile and per-year premiums. The idea of choice arose from the Auto Choice Bill currently before Congress that would give customers the choice between no-fault and tort regimes. Such a choice plan would be politically appealing. Additionally, the selection effects under a choice system would favor per-mile premiums. For any given per-mile price and per-year price, we would expect drivers below some mileage cutoff to choose per-mile premiums, and drivers above the cutoff to choose per-year premiums. As low mileage drivers left the per-year insurance pool, however, the average per-year accident rate in that pool would rise. As per-year premiums rose in consequence, the cutoff would rise and more high-mileage drivers would peel off and sign up for per-mile insurance. Eventually, the per-year insurance system would disappear entirely if the per-mile accident risk for an individual were independent of the amount the individual drove and if monitoring miles were costless. Otherwise, there might be an equilibrium where both systems survived.

A somewhat more daring approach would be to tax insurance premiums to account for accident externalities. Such a tax would be sound policy on its own even if premiums remain weakly linked to mileage, but a premium tax would also encourage insurance companies to switch to per-mile premiums. A premium tax would raise the private gains from reducing driving and with it, accident costs and premiums. A tax would align the insurance company/customer gains with the social gains so that they would rationally switch premiums if the gains exceeded transaction costs. As we have pointed out previously, the premium tax could be most efficiently implemented in a no-fault system, because then competitive insurance premiums would reflect only the frequency of accidents and not the share of accident damages borne, so that the optimal taxes would not depend upon whether one was a good or bad driver.

A final possibility, which the government might help initiate and certify, but could be privately run, would be to meter miles at the pump. This would marry per-mile premiums with the pay-at-the-pump idea, getting the benefits of both. Insurance companies could continue to compete much as they do now, but they would quote risk-classified premiums on a per-mile basis instead of a per-year basis. The per-mile premium for a car could be converted to a per-gallon premium via multiplying by the car's fuel efficiency (in miles per gallon). Unlike uniform per-gallon premiums, these premiums could vary with a driver's risk characteristics. The driver would be issued an insurance card that would need to be used when buying gasoline. The card might double as a credit card so that it could be used in 
the electronic card readers that are currently at most pumps. The number of gallons purchased could be sent electronically to a clearinghouse that reported this number to the insurance company for billing. This system would have the advantage over uniform per-gallon premiums that the price of driving would vary with the risk characteristics of an individual and the territory where the individual lives, but not with the fuel efficiency of the car the individual drives. It would borrow the advantage of pay-atthe-pump proposals that evading premiums would be difficult because you could not purchase gasoline without buying insurance (whether the insurance is bought on credit or otherwise). This system would also eliminate the need for regular odometer checks and the potential problem of odometer fraud. The difficulty with charging non-uniform per-gallon premiums is arbitrage. One person could use another's insurance card or his own card for another vehicle. Such insurance fraud could be limited, however, by checking odometers when a claim is made. If there is a substantial mismatch between the odometer reading and the premiums paid on gasoline, the claim could be denied or pro rated based upon the percentage of premiums paid. The simple principle would be: if you don't pay your insurance premiums, you haven't bought insurance.

\section{Conclusions}

In all three models, the benefits of per-mile premiums are quite large. Benefits reach $\$ 18$ billion nationally, or over $\$ 100$ per car even under the linear model, and are substantially larger (\$25-29 billion) under our preferred regression or calibration models. (The linear model would be roughly accurate if individual elasticities of accidents with respect to miles were not unity as we have assumed, but were .5 , because then the total social elasticity of accidents would be roughly unity as in a linear model, once one takes into account the externalities from two vehicle accidents. $)^{43}$

Most of the benefits, however, are externalities, which is surely one reason that insurance companies have not adopted per-mile premiums on their own. This observation suggests several policy interventions worth considering. States could work to reduce the monitoring costs for insurance companies by reading odometers or certifying odometer checkers. Another approach would be to impose a tax on insurance premiums to account for accident extemalities. Such a tax would gather substantial revenue, perhaps $\$ 60-70$ billion, and would also speed the day when insurance companies charge per-mile premiums. Because the tax would make drivers pay the full accident cost of their driving, it would provide insurance companies and drivers the incentive to strike a contract that would economize on

43 Recall that Hu et al. [1998] estimates of individual elasticities were in this range, though we argue that they were probably biased downward substantially. 
these costs by giving drivers the incentive to drive less. Alternatively, the government could use a carrot, sweetening the pot by providing insurance companies with financial incentives that reflected gains from reducing accident, congestion, and pollution externalities.

Our estimates of the benefits of uniform per-gallon premiums suggest that they are substantially inferior to per-mile premiums (unless transaction costs are substantially reduced). However, per-gallon premiums could be individually tailored at relatively low cost either now or in the near future (per-mile premiums metered at the pump). Uniform per-gallon premiums could be a highly attractive option in countries that do not have fully developed insurance markets and where gasoline does not already carry high taxes.

\section{References.}

Abraham, Kenneth Insurance Law and Regulation : Cases and Materials Second edition. 1995. Foundation press, New York.

Bickelhaupt, David Lynn, General Insurance, 11 th edition, 1983. Irwin: Homewood, Illinois.

Butler, Patrick, Twiss Butler, and Laurie Williams, "Sex-Divided Mileage, Accident and Insurance Cost Data Show That Auto Insurers over Charge Most Women," Journal of Insurance Regulation 6 (3) 1988.

Butler, Patrick. "Measure Expose for Premium Credibility," National Underwriter, April 23, 1990, pp. 418-419.

Butler, Patrick. "Cost-Based Pricing of Individual Automobile Risk Transfer: Car-Mile Exposure Unit Analysis," Journal of Actuarial Practice, pp. 51-84, Vol. 1, No. 11993.

Butler, Patrick and Twiss Butler."Driver Record: a Political Red Herring That Reveals the Basic Flaw in Automobile Insurance Pricing," Journal of Insurance Regulation, pp. 200-234, 8, 1989.

Cooter, Robert and Thomas Ulen, box "You Can't Kill Two Birds with One Stone," pp. 368 of Law and Economics. HarperCollins. 1988.

Dahl, C. And Sterner, 1991, "A Survey of Econometric Gasoline Elasticities," Energy Economics, 13: 3, pp. 203-210.

Dahl, C. And Sterner, 1991, "Analyzing Gasoline Demand Elasticities: a Survey", Energy Economics, 13: 3, Pp. 203-210.

Dougher, Rayola S. And Thomas F. Hogarty, "Paying for Automobile Insurance at the Pump: a Critical Review," Research Study \#076, December 1994, American Petroleum Institute.

Delucci, Mark A., "The Annualized Social Cost of Motor-vehicle Use In the United States, Based on 1990-1991," June 1997, Institute of Transportation Studies, UC Davis.

Devlin, Rose Anne, "Liability Versus No-fault Automobile Insurance 
Regimes an Analysis of the Experience in Quebec," in Contributions to Insurance Economics, Edited by Georges Dionne. Kluwer, 1992: London.

Dewees, Don, David Duff, and Michael Trebilcock. Exploring the Domain of Accident Law: Taking the Facts Seriously. Oxford University Press. New York. 1996.

Fisher, A., L. G. Chestnut and D. M. Violette. "The Value of Reducing Risks of Death: A Note on New Evidence," Journal of Policy Analysis and Management, pp. 88-100, vol. 8, no. 1, 1989.

Gallini, Nancy T. , 1983, “Demand for Gasoline in Canada," Canadian Journal of Economics 16, 299-324.

Goldberg, Pinelopi, "The Effects of the Corporate Average Fuel Efficiency Standards and the U.S.", the Journal of Industrial Economics, March 1998, pp. 1-33.

Goodwin, P. B., "a Review of New Demand Elasticities with Special Reference to Short and Long Run Effects of Price Changes," Joumal of Transport Economics and Policy, 1992, Pp. 155-169.

Green, Jerry. On the Optimal Structure of Liability Laws. Bell Journal of Economics, P. 553-74, 1976.

Hall, J. V., A. M. Winer, M. T. Kleinman, F. W. Lurman, V. Brajer and S. D. Colome. "Valuing the Health Benefits of Clean Air," Science, pp812817 , vol. 255, February, 1992.

Hu, Patricia S., David A. Trumble, Daniel J. Foley, John W. Eberhard, Robert B. Wallace, "Crash Risks of Older Drivers: a Panel Data Analysis," Forthcoming, Journal of Accident Analysis and Prevention, 1998.

Johansson, Olof and Lee Schipper [1997], Measuring the Long-Run Fuel Demand of Cars, Journal of Transport Economics and Policy, Pp. 277292.

Khan, S. "Economic Estimates of the value of life," IEEE Techonology and Society Magazine, pp. 24-31, vol. 5, June, 1986.

Khazzoom, 1997. "What We Know about Uninsured Motorists and How Well We Know What We Know," Discussion Paper 98-09, Resources for the Future.

Litman, Todd "Distance Based Vehicle Insurance as a TDM Strategy," Transportation Quarterly, Vol. 51, No. 3, Summer 1997, pp. 119-138.

Lundy, R. "The Effect of Traffic Volumes and Number of Lanes on Freeway Accident Rates," Cal. Div. of Highways, Traffic Bull. No. II, July, 1964.

Massachussetts Division of Insurance, "Automobile insurance Risk Classification: Equity and Accuracy", 1978.

Nelson, Dale, " Response", Contingencies May/June 1990.

Poterba, James, "Is The Gasoline Tax Regressive?, " In tax policy and the economy David Bradford, editor. National bureau of economic research, MIT press.

Rea, Samuel, A "Insurance Classifications and Social Welfare," in Con- 
tributions to Insurance Economics, edited by George Dionne, 1992. Kluwer: Boston.

Schrank, David, Shawn Turner, and Timothy Lomax, "Urban Roadway Congestion-1982 to 1992. Vol. 2:methodology and Urbanized Area Data," Texas Transportation Institute, 1995.

Shavell, Steven, "Liability Versus Negligence". The Journal of Legal Studies, 1980, pp. 1-26.

Smith, Eric and Randall Wright, "Why Is Automobile Insurance in Philadelphia so Damn Expensive," American Economic Review, 1992, pp. 756-772.

Sugarman, Stephen Pay at the Pump Auto Insurance: The Califormia Vehicle Injury Plan (VIP) For Better Compensation, Fair Funding, and Greater Safety. Institute of governmental studies, UC Berkeley 1993).

Urban Institute, "the Costs of Highway Crashes: Final Report," June 1991.

U.S. Department of Transportation, "Traffic Safery Facts 1996," Dec., 1997.

Vickrey, William. “ Automobile Accidents, Tort Law, Externalities, and Insurance: an Economist's Critique," 33, Law and Contemporary Problems 464 (1968).

Viscusi, Kip. "The Value of Risks to Life and Health," Journal of Economic Literature, 31, pp. 1912-1946, 1993.

Wenzel, T. “Analysis of National Pay-As-You-Drive Insurance Systems and Other Variable Charges," Lawrence Berkeley Lab, Energy and Environment Division, July, 1995.

Williamson, Oliver, Douglas G. Olson, and August Ralston, "Externalities, Insurance, and Disability Analysis," Economica August 1967 p. 235-53. 


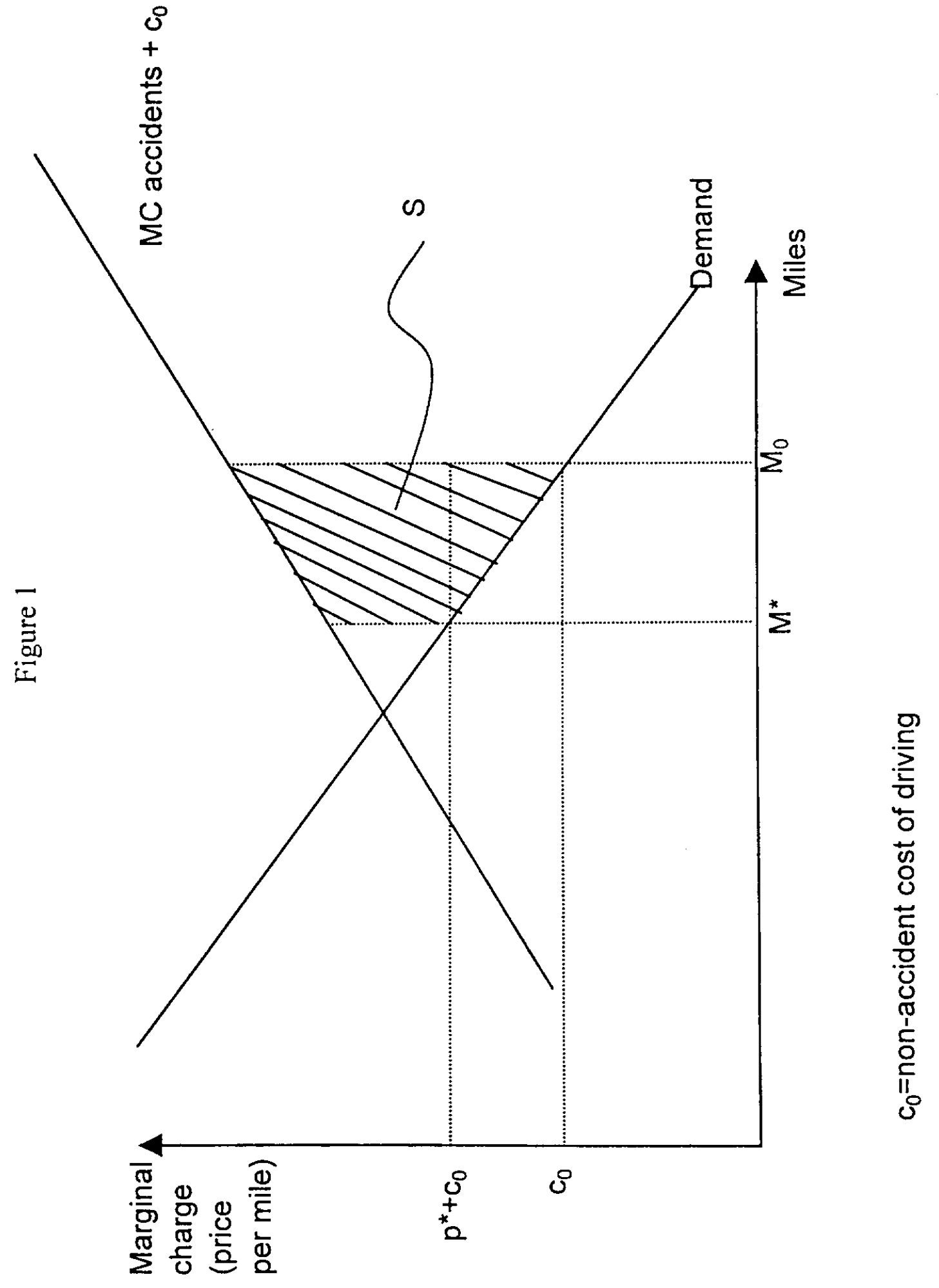



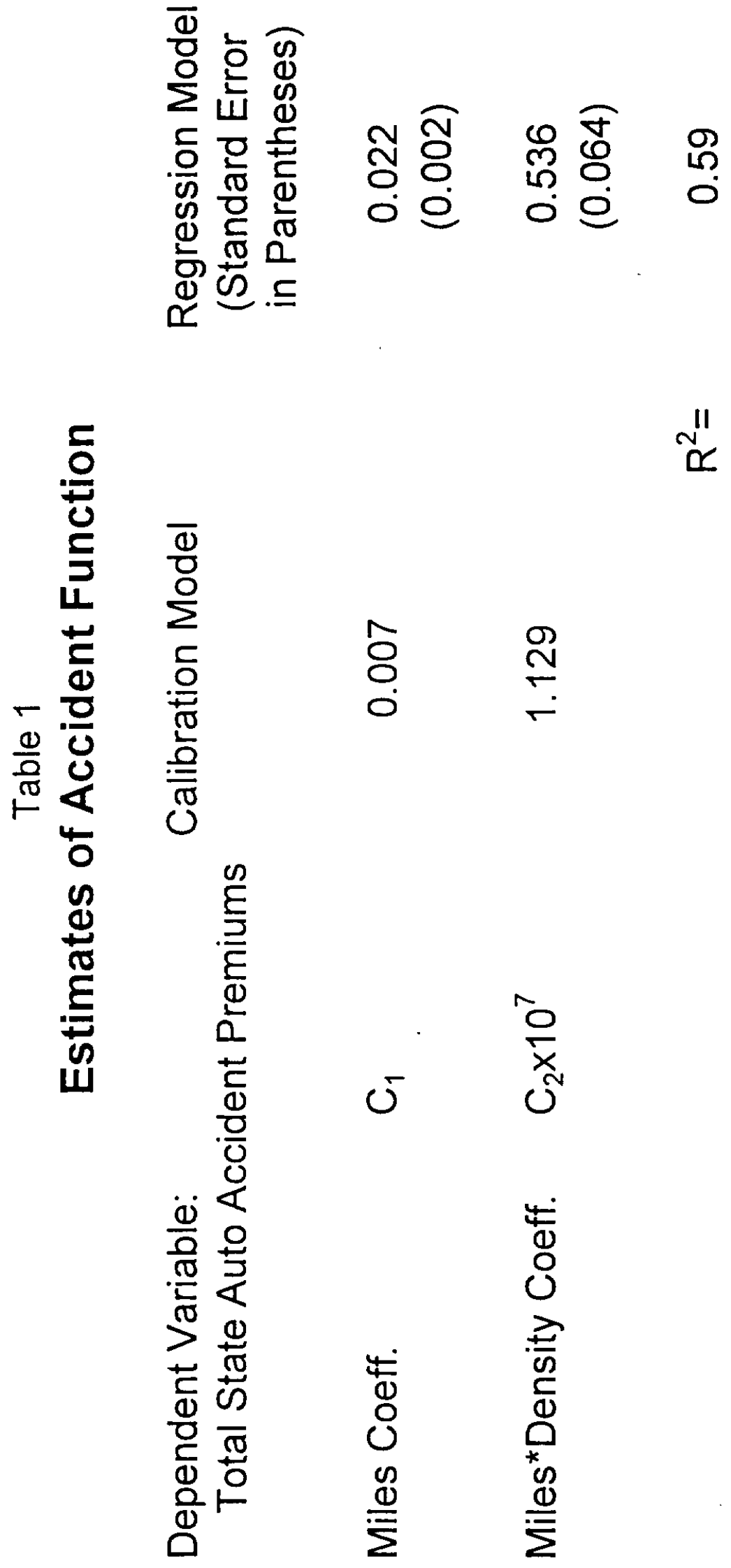
Table 2

Insured Accident Cost

11/30/98 0:00

\begin{tabular}{|c|c|c|}
\hline State & $\begin{array}{c}\text { Vehicle Miles } \\
\text { Traveled } \\
\text { (billions }\end{array}$ & $\begin{array}{l}\text { Lane } \\
\text { Miles }\end{array}$ \\
\hline
\end{tabular}

Estimated Marginal Cost

per year)

\begin{tabular}{|c|c|c|c|c|c|}
\hline Alabama & 51 & 193,000 & 2.4 & 4.3 & 3.3 \\
\hline Alaska & 4 & 27,000 & 5.2 & 8.9 & 6.6 \\
\hline Arizona & 40 & 117,000 & 4.4 & 8.2 & 6.4 \\
\hline Arkansas & 27 & 156,000 & 3.0 & 5.2 & 3.9 \\
\hline California & 276 & 381,000 & 4.1 & 7.8 & 6.6 \\
\hline Colorado & 35 & 174,000 & 4.7 & 8.3 & 6.2 \\
\hline Connecticut & 28 & 43,000 & 6.5 & 12.4 & 10.4 \\
\hline Delaware & 8 & 12,000 & 4.9 & 9.3 & 7.8 \\
\hline Florida & 128 & 244,000 & 4.3 & 8.2 & 6.7 \\
\hline Georgia & 85 & 233,000 & 3.1 & 5.8 & 4.6 \\
\hline Hawaii & 8 & 8,000 & 7.9 & 15.3 & 13.3 \\
\hline Idaho & 12 & 121,000 & 2.4 & 3.9 & 2.9 \\
\hline IItinois & 94 & 286,000 & 4.2 & 7.7 & 6.0 \\
\hline Indiana & 65 & 191,000 & 3.0 & 5.6 & 4.4 \\
\hline lowa & 26 & 230,000 & 3.0 & 4.9 & 3.6 \\
\hline Kansas & 25 & 271,000 & 3.1 & 5.0 & 3.7 \\
\hline Kentucky & 41 & 151,000 & 3.3 & 6.1 & 4.6 \\
\hline Louisiana & 39 & 126,000 & 4.4 & 8.2 & 6.3 \\
\hline Maine & 13 & 46,000 & 3.0 & 5.5 & 4.2 \\
\hline Maryland & 45 & 65,000 & 4.8 & 9.2 & 7.8 \\
\hline Massachusetts & 48 & 65,000 & 6.7 & 12.9 & 11.0 \\
\hline Michigan & 86 & 247,000 & 4.6 & 8.5 & 6.7 \\
\hline Minnesota & 44 & 267,000 & 4.0 & 6.9 & 5.1 \\
\hline Mississippi & 30 & 150,000 & 2.4 & 4.2 & 3.2 \\
\hline Missouri & 59 & 250,000 & 3.0 & 5.4 & 4.1 \\
\hline Montana & 9 & 141,000 & 2.6 & 4.0 & 3.0 \\
\hline Nebraska & 16 & 187,000 & 3.0 & 4.8 & 3.5 \\
\hline Nevada & 14 & 92,000 & 4.9 & 8.4 & 6.2 \\
\hline New Hampshire & 11 & 31,000 & 4.3 & 8.0 & 6.3 \\
\hline New Jersey & 61 & 76,000 & 7.7 & 14.8 & 12.7 \\
\hline New Mexico & 21 & 127,000 & 2.9 & 5.0 & 3.7 \\
\hline New York & 115 & 237,000 & 6.4 & 12.0 & 9.8 \\
\hline North Carolina & 76 & 202,000 & 3.5 & 6.4 & 5.1 \\
\hline North Dakota & 7 & 175,000 & 2.1 & 2.9 & 2.3 \\
\hline Ohio & 101 & 241,000 & 3.6 & 6.8 & 5.4 \\
\hline Oklahoma & 38 & 231,000 & 2.6 & 4.6 & 3.4 \\
\hline Oregon & 30 & 171,000 & 3.8 & 6.7 & 5.0 \\
\hline Pennsylvania & 95 & 247,000 & 5.2 & 9.7 & 7.7 \\
\hline Rhode Island & 7 & 12,000 & 7.3 & 13.8 & 11.4 \\
\hline South Carolina & 39 & 134,000 & 3.5 & 6.5 & 5.0 \\
\hline South Dakota & 8 & 168,000 & 2.5 & 3.6 & 2.7 \\
\hline Tennessee & 56 & 178,000 & 2.8 & 5.1 & 4.0 \\
\hline Texas & 181 & 626,000 & 3.2 & 5.8 & 4.5 \\
\hline Utah & 19 & 85,000 & 3.2 & 5.8 & 4.3 \\
\hline Vermont & 6 & 29,000 & 3.2 & 5.7 & 4.3 \\
\hline Virginia & 70 & 149,000 & 3.5 & 6.5 & 5.3 \\
\hline Washington & 49 & 164,000 & 3.9 & 7.2 & 5.6 \\
\hline West Virginia & 17 & 72,000 & 4.1 & 7.4 & 5.6 \\
\hline Wisconsin & 51 & 228,000 & 3.0 & 5.3 & 4.0 \\
\hline Wyoming & 7 & 73,000 & 1.8 & 3.0 & 2.2 \\
\hline $\begin{array}{l}\text { National Model } \\
\text { (aggregated) }\end{array}$ & 2423 & $8,158,000$ & 4.0 & 7.4 & 5.7 \\
\hline
\end{tabular}


Table 3

Per Mile Premiums \& Driving Reductions

(Not Adjusted for Uninsured Drivers)

\begin{tabular}{|c|c|c|c|c|c|c|}
\hline \multirow{4}{*}{ Model } & \multirow{3}{*}{\multicolumn{2}{|c|}{$\begin{array}{c}A=c, M \\
\text { Linear Model }\end{array}$}} & \multirow{3}{*}{\multicolumn{2}{|c|}{$\begin{array}{c}\text { Gas Elasticity } \quad 0.15 \\
\begin{array}{c}A=c_{1} M+c_{2} M^{2} / L \\
\text { Calibration Model }\end{array}\end{array}$}} & \multirow{3}{*}{\multicolumn{2}{|c|}{$\begin{array}{c}11 / 30 / 980: 00 \\
A=c_{1} M+c_{2} M^{2} / L \\
\text { Regression model }\end{array}$}} \\
\hline & & & & & & \\
\hline & & & & & & \\
\hline & $\begin{array}{l}\text { marginal charge } \\
\text { (cents/mile) }\end{array}$ & VMT reduction & $\begin{array}{l}\text { marginal charge } \\
\text { (cents/mile) }\end{array}$ & VMT reductions & $\begin{array}{c}\text { marginal charge } \\
\text { (cents/mile) }\end{array}$ & VMT reductions \\
\hline Alabama & 2.4 & $6.0 \%$ & 2.3 & $5.7 \%$ & 2.3 & $5.9 \%$ \\
\hline Alaska & 5.2 & $12.0 \%$ & 4.8 & $11.0 \%$ & 5.0 & $11.6 \%$ \\
\hline Arizona & 4.4 & $10.6 \%$ & 4.1 & $9.7 \%$ & 4.2 & $10.1 \%$ \\
\hline Arkansas & 3.0 & $7.7 \%$ & 2.8 & $7.3 \%$ & 2.9 & $7.5 \%$ \\
\hline California & 4.1 & $9.8 \%$ & 3.7 & $9.0 \%$ & 3.8 & $9.2 \%$ \\
\hline Colorado & 4.7 & $11.2 \%$ & 4.3 & $10.3 \%$ & 4.5 & $10.8 \%$ \\
\hline Connecticut & 6.5 & $15.2 \%$ & 5.7 & $13.4 \%$ & 5.9 & $13.9 \%$ \\
\hline Delaware & 4.9 & $12.1 \%$ & 4.4 & $10.9 \%$ & 4.5 & $11.3 \%$ \\
\hline Florida & 4.3 & $11.1 \%$ & 3.9 & $10.1 \%$ & 4.1 & $10.4 \%$ \\
\hline Georgia & 3.1 & $8.4 \%$ & 2.9 & $7.8 \%$ & 3.0 & $8.0 \%$ \\
\hline Hawaii & 7.9 & $18.0 \%$ & 6.8 & $15.4 \%$ & 7.0 & $16.0 \%$ \\
\hline Idaho & 2.4 & $5.7 \%$ & 2.3 & $5.5 \%$ & 2.4 & $5.6 \%$ \\
\hline IIllinois & 4.2 & $10.5 \%$ & 3.8 & $9.6 \%$ & 4.0 & $10.0 \%$ \\
\hline Indiana & 3.0 & $7.8 \%$ & 2.8 & $7.3 \%$ & 2.9 & $7.5 \%$ \\
\hline lowa & 3.0 & $7.5 \%$ & 2.8 & $7.2 \%$ & 2.9 & $7.4 \%$ \\
\hline Kansas & 3.1 & $8.1 \%$ & 3.0 & $7.7 \%$ & 3.1 & $7.9 \%$ \\
\hline Kentucky & 3.3 & $8.5 \%$ & 3.1 & $7.9 \%$ & 3.2 & $8.2 \%$ \\
\hline Louisiana & 4.4 & $11.2 \%$ & 4.1 & $10.2 \%$ & 4.2 & $10.6 \%$ \\
\hline Maine & 3.0 & $7.4 \%$ & 2.8 & $7.0 \%$ & 2.9 & $7.2 \%$ \\
\hline Maryland & 4.8 & $11.8 \%$ & 4.3 & $10.6 \%$ & 4.5 & $11.0 \%$ \\
\hline Massachusetts & 6.7 & $16.4 \%$ & 5.8 & $14.2 \%$ & 6.1 & $14.8 \%$ \\
\hline Michigan & 4.6 & $12.0 \%$ & 4.2 & $10.9 \%$ & 4.4 & $11.4 \%$ \\
\hline Minnesota & 4.0 & $9.7 \%$ & 3.7 & $9.1 \%$ & 3.9 & $9.5 \%$ \\
\hline Mississippi & 2.4 & $6.0 \%$ & 2.3 & $5.7 \%$ & 2.3 & $5.9 \%$ \\
\hline Missouri & 3.0 & $7.8 \%$ & 2.8 & $7.3 \%$ & 2.9 & $7.6 \%$ \\
\hline Montana & 2.6 & $6.1 \%$ & 2.5 & $6.0 \%$ & 2.6 & $6.1 \%$ \\
\hline Nebraska & 3.0 & $7.5 \%$ & 2.9 & $7.2 \%$ & 3.0 & $7.4 \%$ \\
\hline Nevada & 4.9 & $11.5 \%$ & 4.5 & $10.7 \%$ & 4.7 & $11.2 \%$ \\
\hline New Hampshire & 4.3 & $10.6 \%$ & 4.0 & $9.8 \%$ & 4.1 & $10.2 \%$ \\
\hline New Jersey & 7.7 & $19.4 \%$ & 6.5 & $16.4 \%$ & 6.8 & $17.2 \%$ \\
\hline New Mexico & 2.9 & $7.0 \%$ & 2.7 & $6.6 \%$ & 2.8 & $6.9 \%$ \\
\hline New York & 6.4 & $15.6 \%$ & 5.6 & $13.7 \%$ & 5.9 & $14.4 \%$ \\
\hline North Carolina & 3.5 & $8.7 \%$ & 3.2 & $8.1 \%$ & 3.3 & $8.3 \%$ \\
\hline North Dakota & 2.1 & $5.1 \%$ & 2.1 & $5.0 \%$ & 2.1 & $5.1 \%$ \\
\hline Ohio & 3.6 & $9.1 \%$ & 3.3 & $8.4 \%$ & 3.5 & $8.7 \%$ \\
\hline Oklahoma & 2.6 & $6.8 \%$ & 2.5 & $6.5 \%$ & 2.6 & $6.7 \%$ \\
\hline Oregon & 3.8 & $9.0 \%$ & 3.6 & $8.5 \%$ & 3.7 & $8.8 \%$ \\
\hline Pennsylvania & 5.2 & $12.9 \%$ & 4.7 & $11.6 \%$ & 4.9 & $12.1 \%$ \\
\hline Rhode Island & 7.3 & $17.6 \%$ & 6.3 & $15.2 \%$ & 6.6 & $16.0 \%$ \\
\hline South Carolina & 3.5 & $9.2 \%$ & 3.3 & $8.5 \%$ & 3.4 & $8.8 \%$ \\
\hline South Dakota & 2.5 & $6.1 \%$ & 2.4 & $6.0 \%$ & 2.5 & $6.1 \%$ \\
\hline Tennessee & 2.8 & $7.0 \%$ & 2.6 & $6.6 \%$ & 2.7 & $6.8 \%$ \\
\hline Texas & 3.2 & $8.0 \%$ & 3.0 & $7.5 \%$ & 3.1 & $7.8 \%$ \\
\hline Utah & 3.2 & $7.7 \%$ & 3.0 & $7.3 \%$ & 3.1 & $7.5 \%$ \\
\hline Vermont & 3.2 & $7.9 \%$ & 3.0 & $7.4 \%$ & 3.1 & $7.7 \%$ \\
\hline Virginia & 3.5 & $8.7 \%$ & 3.2 & $8.1 \%$ & 3.3 & $8.3 \%$ \\
\hline Washington & 3.9 & $9.3 \%$ & 3.6 & $8.6 \%$ & 3.8 & $9.0 \%$ \\
\hline West Virginia & 4.1 & $10.3 \%$ & 3.8 & $9.5 \%$ & 4.0 & $10.0 \%$ \\
\hline Wisconsin & 3.0 & $7.4 \%$ & 2.8 & $7.0 \%$ & 2.9 & $7.2 \%$ \\
\hline Wyoming & 1.8 & $4.6 \%$ & 1.8 & $4.4 \%$ & 1.8 & $4.5 \%$ \\
\hline $\begin{array}{l}\text { U.S. Total } \\
\text { (disaggregated sum) }\end{array}$ & & $10.0 \%$ & & $9.2 \%$ & & $9.5 \%$ \\
\hline National Model & & & & & & \\
\hline (aggregated) & 4.0 & $10.2 \%$ & 3.7 & $9.4 \%$ & 3.9 & $9.7 \%$ \\
\hline
\end{tabular}


Table 4

Accident Savings from Per Mile Premiums

(Net of Lost Driving Benefits)

Gas Elasticity 0.15

\begin{tabular}{|c|c|c|c|c|c|c|}
\hline \multirow[t]{2}{*}{ Model } & \multicolumn{2}{|c|}{$\begin{array}{c}A=c_{1} M \\
\text { Linear Model }\end{array}$} & \multicolumn{2}{|c|}{$\begin{array}{c}A=c_{1} M+c_{2} M^{2} / L \\
\text { Calibration Model }\end{array}$} & \multicolumn{2}{|c|}{$\begin{array}{l}A=c_{1} M+c_{2} M^{2} / L \\
\text { Regression model }\end{array}$} \\
\hline & $\begin{array}{c}\text { total } \\
\text { (dollars in miltions) }\end{array}$ & $\begin{array}{c}\text { per insured vehicle } \\
\$\end{array}$ & $\begin{array}{l}\text { total } \\
\text { (dollars in millions }\end{array}$ & $\begin{array}{c}\text { per insured vehicle } \\
\$\end{array}$ & $\begin{array}{l}\text { total } \\
\text { (dollars in millions }\end{array}$ & $\begin{array}{c}\text { per insured vehicle } \\
\mathbf{S}\end{array}$ \\
\hline Alabama & 36 & 14 & 89 & 34 & 63 & 24 \\
\hline Alaska & 13 & 38 & 28 & 83 & 17 & 51 \\
\hline Arizona & 93 & 33 & 223 & 79 & 157 & 56 \\
\hline Arkansas & 31 & 16 & 70 & 38 & 48 & 26 \\
\hline California & 548 & 34 & 1391 & 86 & 1111 & 68 \\
\hline Colorado & 91 & 34 & 207 & 76 & 137 & 50 \\
\hline Connecticut & 138 & 59 & 328 & 141 & 256 & 109 \\
\hline Delaware & 22 & 43 & 54 & 106 & 44 & 85 \\
\hline Florida & 306 & 36 & 752 & 88 & 615 & 72 \\
\hline Georgia & 112 & 21 & 277 & 52 & 224 & 42 \\
\hline Hawaii & 57 & 81 & 132 & 188 & 105 & 150 \\
\hline Idaho & 8 & 11 & 18 & 23 & 11 & 14 \\
\hline Illinois & 205 & 27 & 491 & 65 & 365 & 48 \\
\hline Indiana & 75 & 18 & 187 & 45 & 142 & 34 \\
\hline lowa & 29 & 13 & 63 & 29 & 41 & 19 \\
\hline Kansas & 32 & 15 & 66 & 31 & 44 & 21 \\
\hline Kentucky & 58 & 21 & 140 & 50 & 102 & 37 \\
\hline Louisiana & 96 & 39 & 227 & 92 & 167 & 68 \\
\hline Maine & 14 & 15 & 34 & 37 & 24 & 26 \\
\hline Maryland & 127 & 38 & 314 & 93 & 255 & 76 \\
\hline Massachusetts & 263 & 66 & 622 & 155 & 511 & 128 \\
\hline Michigan & 237 & 33 & 562 & 78 & 442 & 61 \\
\hline Minnesota & 85 & 26 & 191 & 58 & 126 & 38 \\
\hline Mississippi & 21 & 15 & 50 & 35 & 34 & 24 \\
\hline Missouri & 69 & 19 & 166 & 45 & 121 & 33 \\
\hline Montana & 8 & 11 & 15 & 22 & 9 & 13 \\
\hline Nebraska & 18 & 13 & 36 & 27 & 23 & 17 \\
\hline Nevada & 39 & 39 & 86 & 85 & 54 & 54 \\
\hline New Hampshire & 24 & 28 & 59 & 68 & 43 & 50 \\
\hline New Jersey & 453 & 86 & 1040 & 198 & 901 & 171 \\
\hline New Mexico & 21 & 19 & 49 & 44 & 32 & 28 \\
\hline New York & 574 & 60 & 1339 & 139 & 1045 & 109 \\
\hline North Carolina & 114 & 19 & 282 & 48 & 211 & 36 \\
\hline North Dakota & 4 & 7 & 6 & 13 & 4 & 8 \\
\hline Ohio & 165 & 21 & 410 & 52 & 314 & 40 \\
\hline Oklahoma & 35 & 15 & 80 & 34 & 56 & 24 \\
\hline Oregon & 52 & 22 & 118 & 51 & 74 & 32 \\
\hline Pennsylvania & 317 & 38 & 749 & 90 & 565 & 68 \\
\hline Rhode Island & 44 & 68 & 101 & 157 & 80 & 124 \\
\hline South Carolina & 63 & 23 & 151 & 56 & 113 & 42 \\
\hline South Dakota & 6 & 10 & 10 & 18 & 7 & 12 \\
\hline Tennessee & 55 & 16 & 136 & 39 & 99 & 28 \\
\hline Texas & 230 & 24 & 559 & 59 & 409 & 43 \\
\hline Utah & 23 & 18 & 55 & 43 & 36 & 28 \\
\hline Vermont & 8 & 17 & 18 & 41 & 13 & 28 \\
\hline Virginia & 105 & 21 & 264 & 54 & 206 & 42 \\
\hline Washington & 90 & 27 & 216 & 64 & 148 & 44 \\
\hline West Virginia & 37 & 29 & 86 & 68 & 61 & 48 \\
\hline Wisconsin & 56 & 15 & 134 & 37 & 91 & 25 \\
\hline Wyoming & 3 & 8 & 6 & 16 & 4 & 10 \\
\hline $\begin{array}{l}\text { U.S. Total } \\
\text { (disaggregated sum) }\end{array}$ & 5310 & 31 & 12686 & 75 & 9762 & 58 \\
\hline $\begin{array}{l}\text { National Model } \\
\text { (aggregated) }\end{array}$ & & & & & & \\
\hline (aggregated) & 4954 & 29 & 11813 & 70 & 8476 & 50 \\
\hline
\end{tabular}


Table 5

Per Gallon Premiums \& Driving Reductions

(Not Adjusted for Uninsured Drivers)

\begin{tabular}{|c|c|c|c|c|c|c|}
\hline \multirow{4}{*}{$\begin{array}{l}\text { Model } \\
\text { States }\end{array}$} & \multirow{3}{*}{\multicolumn{4}{|c|}{$\begin{array}{c}\text { Gas Elasticity } \quad 0.15 \\
\qquad \begin{array}{c}A=c_{1} M+c_{2} M^{2} / L \\
\text { Calibration Model }\end{array}\end{array}$}} & \multirow{3}{*}{\multicolumn{2}{|c|}{$\begin{array}{l}11 / 30 / 980: 00 \\
A=c_{1} M+c_{2} M^{2} / L \\
\text { Regression model }\end{array}$}} \\
\hline & & & & & & \\
\hline & & & & & & \\
\hline & $\begin{array}{c}\text { marginal charge } \\
\text { (cents/gallon) }\end{array}$ & VMT reductions & $\begin{array}{l}\text { marginal charge } \\
\text { (cents/gallon) }\end{array}$ & VMT reductions & $\begin{array}{c}\text { marginal charge } \\
\text { (cents/gallon) }\end{array}$ & VMT reductions \\
\hline Alabama & 45 & $5.5 \%$ & 41 & $5.1 \%$ & 43 & $5.3 \%$ \\
\hline Alaska & 92 & $10.5 \%$ & 82 & $9.2 \%$ & 88 & $10.0 \%$ \\
\hline Arizona & 80 & $9.3 \%$ & 70 & $8.2 \%$ & 74 & $8.7 \%$ \\
\hline Arkansas & 55 & $6.9 \%$ & 50 & $6.3 \%$ & 53 & $6.7 \%$ \\
\hline California & 73 & $8.7 \%$ & 64 & $7.6 \%$ & 67 & $7.9 \%$ \\
\hline Colorado & 84 & $9.8 \%$ & 74 & $8.7 \%$ & 79 & $9.3 \%$ \\
\hline Connecticut & 113 & $13.0 \%$ & 94 & $10.8 \%$ & 99 & $11.4 \%$ \\
\hline Delaware & 87 & $10.6 \%$ & 74 & $9.0 \%$ & 78 & $9.5 \%$ \\
\hline Florida & 69 & $8.8 \%$ & 61 & $7.7 \%$ & 69 & $8.7 \%$ \\
\hline Georgia & 46 & $6.1 \%$ & 43 & $5.7 \%$ & 50 & $6.6 \%$ \\
\hline Hawaii & 117 & $13.0 \%$ & 98 & $10.9 \%$ & 111 & $12.4 \%$ \\
\hline Idaho & 40 & $4.6 \%$ & 38 & $4.4 \%$ & 43 & $4.9 \%$ \\
\hline Illinois & 64 & $7.8 \%$ & 58 & $7.1 \%$ & 68 & $8.4 \%$ \\
\hline Indiana & 46 & $5.8 \%$ & 43 & $5.4 \%$ & 49 & $6.2 \%$ \\
\hline lowa & 43 & $5.3 \%$ & 42 & $5.2 \%$ & 51 & $6.3 \%$ \\
\hline Kansas & 47 & $5.9 \%$ & 45 & $5.7 \%$ & 54 & $6.8 \%$ \\
\hline Kentucky & 51 & $6.4 \%$ & 48 & $6.0 \%$ & 56 & $7.0 \%$ \\
\hline Louisiana & 71 & $8.7 \%$ & 63 & $7.8 \%$ & 72 & $8.9 \%$ \\
\hline Maine & 44 & $5.3 \%$ & 42 & $5.0 \%$ & 51 & $6.1 \%$ \\
\hline Maryland & 78 & $9.5 \%$ & 68 & $8.2 \%$ & 74 & $9.0 \%$ \\
\hline Massachusetts & 101 & $12.1 \%$ & 85 & $10.2 \%$ & 97 & $11.6 \%$ \\
\hline Michigan & 73 & $9.4 \%$ & 64 & $8.3 \%$ & 73 & $9.4 \%$ \\
\hline Minnesota & 65 & $7.8 \%$ & 59 & $7.1 \%$ & 66 & $7.9 \%$ \\
\hline Mississippi & 39 & $4.9 \%$ & 37 & $4.6 \%$ & 41 & $5.1 \%$ \\
\hline Missouri & 49 & $6.2 \%$ & 45 & $5.7 \%$ & 51 & $6.4 \%$ \\
\hline Montana & 41 & $4.8 \%$ & 40 & $4.6 \%$ & 46 & $5.3 \%$ \\
\hline Nebraska & 50 & $6.1 \%$ & 47 & $5.8 \%$ & 52 & $6.4 \%$ \\
\hline Nevada & 74 & $8.6 \%$ & 68 & $7.8 \%$ & 81 & $9.3 \%$ \\
\hline New Hampshire & 62 & $7.5 \%$ & 57 & $6.9 \%$ & 69 & $8.4 \%$ \\
\hline New Jersey & 110 & $13.7 \%$ & 92 & $11.4 \%$ & 106 & $13.2 \%$ \\
\hline New Mexico & 45 & $5.5 \%$ & 43 & $5.1 \%$ & 48 & $5.8 \%$ \\
\hline New York & 101 & $12.2 \%$ & 86 & $10.3 \%$ & 96 & $11.5 \%$ \\
\hline North Carolina & 56 & $6.9 \%$ & 51 & $6.3 \%$ & 57 & $7.0 \%$ \\
\hline North Dakota & 36 & $4.3 \%$ & 35 & $4.2 \%$ & 37 & $4.5 \%$ \\
\hline Ohio & 58 & $7.2 \%$ & 53 & $6.5 \%$ & 59 & $7.2 \%$ \\
\hline Oklahoma & 41 & $5.2 \%$ & 39 & $4.9 \%$ & 44 & $5.6 \%$ \\
\hline Oregon & 61 & $7.0 \%$ & 56 & $6.5 \%$ & 64 & $7.4 \%$ \\
\hline Pennsylvania & 72 & $8.8 \%$ & 66 & $8.0 \%$ & 80 & $9.8 \%$ \\
\hline Rhode Island & 113 & $13.4 \%$ & 94 & $11.2 \%$ & 106 & $12.5 \%$ \\
\hline South Carolina & 51 & $6.5 \%$ & 48 & $6.1 \%$ & 57 & $7.3 \%$ \\
\hline South Dakota & 40 & $4.9 \%$ & 39 & $4.8 \%$ & 44 & $5.3 \%$ \\
\hline Tennessee & 47 & $5.8 \%$ & 43 & $5.4 \%$ & 47 & $5.8 \%$ \\
\hline Texas & 50 & $6.3 \%$ & 46 & $5.8 \%$ & 53 & $6.6 \%$ \\
\hline Utah & 54 & $6.3 \%$ & 50 & $5.8 \%$ & 55 & $6.4 \%$ \\
\hline Vermont & 51 & $6.2 \%$ & 47 & $5.7 \%$ & 53 & $6.5 \%$ \\
\hline Virginia & 53 & $6.6 \%$ & 49 & $6.0 \%$ & 56 & $6.9 \%$ \\
\hline Washington & 56 & $6.5 \%$ & 53 & $6.1 \%$ & 63 & $7.4 \%$ \\
\hline West Virginia & 66 & $8.1 \%$ & 59 & $7.3 \%$ & 67 & $8.3 \%$ \\
\hline Wisconsin & 50 & $6.0 \%$ & 46 & $5.6 \%$ & 50 & $6.1 \%$ \\
\hline Wyoming & 31 & $3.7 \%$ & 30 & $3.6 \%$ & 33 & $4.0 \%$ \\
\hline $\begin{array}{l}\text { U.S. Total } \\
\text { (disagaregated sum }\end{array}$ & & $79 \%$ & & $70 \%$ & & \\
\hline $\begin{array}{l}\text { (disaggregated sum) } \\
\text { National Model }\end{array}$ & & $7.9 \%$ & & $7.0 \%$ & & $7.9 \%$ \\
\hline (aggregated) & 64 & $8.0 \%$ & 58 & $7.2 \%$ & 65 & $8.1 \%$ \\
\hline
\end{tabular}


Table 6

Accident Savings from Per Gallon Premiums

(Net of Lost Driving Benefits)

Gas Elasticity 0.15

\begin{tabular}{|c|c|c|c|c|c|c|}
\hline \multirow[t]{2}{*}{ Model } & \multicolumn{2}{|c|}{$\begin{array}{c}A=c_{1} M \\
\text { Linear Model }\end{array}$} & \multicolumn{2}{|c|}{$\begin{array}{c}A=c_{1} M+c_{2} M^{2} / L \\
\text { Calibration Model }\end{array}$} & \multicolumn{2}{|c|}{$\begin{array}{l}A=c_{1} M+c_{2} M^{2} / L \\
\text { Regression model }\end{array}$} \\
\hline & $\begin{array}{c}\text { total } \\
\text { (dollars in millions) }\end{array}$ & per insured vehicle & total & per insured vehicle & total & per insured vehicle \\
\hline States & (dollars in millions) & $s$ & (dollars in millions) & $\$$ & (dollars in millions) & \\
\hline Alabama & 34 & 13 & 81 & 31 & 57 & 22 \\
\hline Alaska & 12 & 35 & 24 & 73 & 17 & 50 \\
\hline Arizona & 86 & 30 & 196 & 69 & 147 & 52 \\
\hline Arkansas & 28 & 15 & 63 & 34 & 43 & 23 \\
\hline California & 507 & 31 & 1222 & 75 & 1019 & 63 \\
\hline Colorado & 84 & 31 & 182 & 67 & 129 & 47 \\
\hline Connecticut & 127 & 54 & 280 & 120 & 235 & 101 \\
\hline Delaware & 20 & 40 & 47 & 92 & 39 & 76 \\
\hline Florida & 277 & 33 & 619 & 73 & 519 & 61 \\
\hline Georgia & 99 & 19 & 219 & 41 & 178 & 34 \\
\hline Hawaii & 50 & 71 & 103 & 147 & 95 & 136 \\
\hline Idaho & 8 & 10 & 15 & 20 & 11 & 13 \\
\hline Illinois & 183 & 24 & 395 & 52 & 319 & 42 \\
\hline Indiana & 67 & 16 & 150 & 36 & 120 & 29 \\
\hline lowa & 25 & 12 & 50 & 23 & 36 & 17 \\
\hline Kansas & 28 & 13 & 53 & 25 & 38 & 18 \\
\hline Kentucky & 52 & 19 & 113 & 41 & 88 & 32 \\
\hline Louisiana & 87 & 35 & 186 & 75 & 146 & 59 \\
\hline Maine & 12 & 13 & 27 & 29 & 22 & 23 \\
\hline Maryland & 115 & 34 & 259 & 77 & 223 & 66 \\
\hline Massachusetts & 234 & 58 & 491 & 123 & 441 & $\$ 10$ \\
\hline Michigan & 214 & 30 & 460 & 64 & 367 & 51 \\
\hline Minnesota & 77 & 24 & 160 & 49 & 114 & 35 \\
\hline Mississippi & 19 & 13 & 43 & 29 & 30 & 21 \\
\hline Missouri & 63 & 17 & 138 & 38 & 103 & 28 \\
\hline Montana & 7 & 10 & 12 & 19 & 9 & 13 \\
\hline Nebraska & 16 & 12 & 31 & 23 & 21 & 16 \\
\hline Nevada & 35 & 35 & 69 & 69 & 51 & 51 \\
\hline New Hampshire & 21 & 25 & 46 & 53 & 38 & 44 \\
\hline New Jersey & 396 & 75 & 803 & 153 & 740 & 141 \\
\hline New Mexico & 19 & 17 & 40 & 36 & 29 & 26 \\
\hline New York & 518 & 54 & 1090 & 114 & 913 & 95 \\
\hline North Carolina & 104 & 18 & 234 & 40 & 186 & 32 \\
\hline North Dakota & 3 & 7 & 5 & 11 & 4 & 8 \\
\hline Ohio & 150 & 19 & 338 & 43 & 272 & 34 \\
\hline Oklahoma & 31 & 13 & 65 & 28 & 47 & 20 \\
\hline Oregon & 47 & 20 & 97 & 42 & 71 & 30 \\
\hline Pennsylvania & 273 & 33 & 573 & 69 & 491 & 59 \\
\hline Rhode Island & 40 & 61 & 82 & 126 & 70 & 108 \\
\hline South Carolina & 55 & 20 & 118 & 44 & 95 & 35 \\
\hline South Dakota & 5 & 9 & 9 & 16 & 6 & 11 \\
\hline Tennessee & 50 & 14 & 116 & 33 & 87 & 25 \\
\hline Texas & 208 & 22 & 461 & 49 & 356 & 38 \\
\hline Utah & 21 & 17 & 47 & 37 & 34 & 27 \\
\hline Vermont & 7 & 16 & 15 & 34 & 11 & 25 \\
\hline Virginia & 94 & 19 & 213 & 43 & 178 & 36 \\
\hline Washington & 78 & 23 & 169 & 50 & 137 & 41 \\
\hline West Virginia & 33 & 26 & 71 & 56 & 54 & 42 \\
\hline Wisconsin & 51 & 14 & 113 & 31 & 82 & 23 \\
\hline Wyoming & 3 & 7 & 5 & 14 & 4 & 9 \\
\hline $\begin{array}{l}\text { U.S. Total } \\
\text { (disaggregated sum) }\end{array}$ & 4776 & 28 & 10402 & 61 & 8520 & 50 \\
\hline National Model & & & & & & \\
\hline (aggregated) & 4480 & 26 & 9727 & 58 & 7526 & 44 \\
\hline
\end{tabular}


Table 7

Optimal Premiums \& Driving Reductions

(Not Adjusted for Uninsured Drivers)

Gas Elasticity $\quad 0.15$

$11 / 30 / 980: 00$

\begin{tabular}{|c|c|c|c|c|c|c|}
\hline \multirow{2}{*}{$\begin{array}{l}\text { Model } \\
\text { States }\end{array}$} & \multicolumn{2}{|c|}{$\begin{array}{l}A=c_{1} M \\
\text { Linear Model }\end{array}$} & \multicolumn{2}{|c|}{$\begin{array}{c}A=c_{1} M+c_{2} M^{2} / L \\
\text { Calibration Model }\end{array}$} & \multicolumn{2}{|c|}{$\begin{array}{l}A=c_{1} M+c_{2} M^{2} / L \\
\text { Regession model }\end{array}$} \\
\hline & $\begin{array}{c}\text { marginal charge } \\
\text { (cents/mile) }\end{array}$ & VMT reductions & $\begin{array}{c}\text { marginal charge } \\
\text { (cents/mile) }\end{array}$ & VMT reductions & $\begin{array}{c}\text { marginal charge } \\
\text { (cents/mile) }\end{array}$ & VMT reductions \\
\hline Alabama & 2.4 & $6.0 \%$ & 3.9 & $9.9 \%$ & 3.2 & $8.0 \%$ \\
\hline Alaska & 5.2 & $12.0 \%$ & 7.6 & $17.6 \%$ & 6.2 & $14.3 \%$ \\
\hline Arizona & 4.4 & $10.6 \%$ & 7.0 & $16.6 \%$ & 5.9 & $14.0 \%$ \\
\hline Arkansas & 3.0 & $7.7 \%$ & 4.7 & $12.0 \%$ & 3.7 & $9.5 \%$ \\
\hline California & 4.1 & $9.8 \%$ & 6.6 & $16.0 \%$ & 5.9 & $14.2 \%$ \\
\hline Colorado & 4.7 & $11.2 \%$ & 7.0 & $16.9 \%$ & 5.8 & $13.8 \%$ \\
\hline Connecticut & 6.5 & $15.2 \%$ & 9.7 & $22.8 \%$ & 8.8 & $20.6 \%$ \\
\hline Delaware & 4.9 & $12.1 \%$ & 7.6 & $18.9 \%$ & 6.8 & $16.9 \%$ \\
\hline Florida & 4.3 & $11.1 \%$ & 6.8 & $17.5 \%$ & 6.0 & $15.4 \%$ \\
\hline Georgia & 3.1 & $8.4 \%$ & 5.1 & $13.6 \%$ & 4.3 & $11.4 \%$ \\
\hline Hawaii & 7.9 & $18.0 \%$ & 11.5 & $26.1 \%$ & 10.7 & $24.3 \%$ \\
\hline Idaho & 2.4 & $5.7 \%$ & 3.7 & $8.7 \%$ & 2.8 & $6.7 \%$ \\
\hline Illinois & 4.2 & $10.5 \%$ & 6.5 & $16.4 \%$ & 5.5 & $13.8 \%$ \\
\hline Indiana & 3.0 & $7.8 \%$ & 4.9 & $12.7 \%$ & 4.1 & $10.5 \%$ \\
\hline lowa & 3.0 & $7.5 \%$ & 4.5 & $11.3 \%$ & 3.5 & $8.8 \%$ \\
\hline Kansas & 3.1 & $8.1 \%$ & 4.6 & $11.8 \%$ & 3.6 & $9.3 \%$ \\
\hline Kentucky & 3.3 & $8.5 \%$ & 5.3 & $13.6 \%$ & 4.4 & $11.1 \%$ \\
\hline Louisiana & 4.4 & $11.2 \%$ & 6.9 & $17.3 \%$ & 5.8 & $14.5 \%$ \\
\hline Maine & 3.0 & $7.4 \%$ & 4.9 & $12.0 \%$ & 4.0 & $9.8 \%$ \\
\hline Maryland & 4.8 & $11.8 \%$ & 7.6 & $18.6 \%$ & 6.8 & $16.7 \%$ \\
\hline Massachusetts & 6.7 & $16.4 \%$ & 9.9 & $24.2 \%$ & 9.1 & $22.2 \%$ \\
\hline Michigan & 4.6 & $12.0 \%$ & 7.1 & $18.5 \%$ & 6.0 & $15.7 \%$ \\
\hline Minnesota & 4.0 & $9.7 \%$ & 6.0 & $14.8 \%$ & 4.8 & $11.8 \%$ \\
\hline Mississippi & 2.4 & $6.0 \%$ & 3.9 & $9.7 \%$ & 3.0 & $7.6 \%$ \\
\hline Missouri & 3.0 & $7.8 \%$ & 4.8 & $12.4 \%$ & 3.9 & $10.0 \%$ \\
\hline Montana & 2.6 & $6.1 \%$ & 3.7 & $8.8 \%$ & 2.9 & $6.9 \%$ \\
\hline Nebraska & 3.0 & $7.5 \%$ & 4.4 & $10.9 \%$ & 3.4 & $8.5 \%$ \\
\hline Nevada & 4.9 & $11.5 \%$ & 7.2 & $17.0 \%$ & 5.8 & $13.8 \%$ \\
\hline New Hampshire & 4.3 & $10.6 \%$ & 6.8 & $16.7 \%$ & 5.7 & $14.1 \%$ \\
\hline New Jersey & 7.7 & $19.4 \%$ & 10.9 & $27.5 \%$ & 10.1 & $25.6 \%$ \\
\hline New Mexico & 2.9 & $7.0 \%$ & 4.5 & $11.0 \%$ & 3.5 & $8.6 \%$ \\
\hline New York & 6.4 & $15.6 \%$ & 9.4 & $23.1 \%$ & 8.4 & $20.6 \%$ \\
\hline North Carolina & 3.5 & $8.7 \%$ & 5.6 & $14.0 \%$ & 4.7 & $11.8 \%$ \\
\hline North Dakota & 2.1 & $5.1 \%$ & 2.8 & $6.8 \%$ & 2.2 & $5.5 \%$ \\
\hline Ohio & 3.6 & $9.1 \%$ & 5.8 & $14.7 \%$ & 5.0 & $12.5 \%$ \\
\hline Oklahoma & 2.6 & $6.8 \%$ & 4.1 & $10.8 \%$ & 3.3 & $8.5 \%$ \\
\hline Oregon & 3.8 & $9.0 \%$ & 5.9 & $13.9 \%$ & 4.7 & $11.1 \%$ \\
\hline Pennsylvania & 5.2 & $12.9 \%$ & 7.9 & $19.7 \%$ & 6.8 & $17.0 \%$ \\
\hline Rhode Island & 7.3 & $17.6 \%$ & 10.5 & $25.4 \%$ & 9.5 & $23.0 \%$ \\
\hline South Carolina & 3.5 & $9.2 \%$ & 5.6 & $14.5 \%$ & 4.6 & $12.0 \%$ \\
\hline South Dakota & 2.5 & $6.1 \%$ & 3.4 & $8.3 \%$ & 2.7 & $6.6 \%$ \\
\hline Tennessee & 2.8 & $7.0 \%$ & 4.6 & $11.6 \%$ & 3.7 & $9.5 \%$ \\
\hline Texas & 3.2 & $8.0 \%$ & 5.1 & $13.0 \%$ & 4.2 & $10.6 \%$ \\
\hline Utah & 3.2 & $7.7 \%$ & 5.1 & $12.3 \%$ & 4.1 & $9.8 \%$ \\
\hline Vermont & 3.2 & $7.9 \%$ & 5.0 & $12.5 \%$ & 4.0 & $10.0 \%$ \\
\hline Virginia & 3.5 & $8.7 \%$ & 5.7 & $14.3 \%$ & 4.8 & $12.2 \%$ \\
\hline Washington & 3.9 & $9.3 \%$ & 6.2 & $14.8 \%$ & 5.1 & $12.3 \%$ \\
\hline West Virginia & 4.1 & $10.3 \%$ & 6.4 & $16.0 \%$ & 5.2 & $13.1 \%$ \\
\hline Wisconsin & 3.0 & $7.4 \%$ & 4.8 & $11.8 \%$ & 3.8 & $9.4 \%$ \\
\hline Wyoming & 1.8 & $4.6 \%$ & 2.8 & $7.0 \%$ & 2.1 & $5.3 \%$ \\
\hline $\begin{array}{l}\text { U.S. Total } \\
\text { (disaggregated sum) }\end{array}$ & & $10.0 \%$ & & $15.7 \%$ & & $13.4 \%$ \\
\hline $\begin{array}{l}\text { National Model } \\
\text { (aggregated) }\end{array}$ & & & & & & \\
\hline (aggregated) & 4.0 & $10.2 \%$ & 6.3 & $15.9 \%$ & 5.3 & $13.3 \%$ \\
\hline
\end{tabular}


Table 8

Accident Savings from Optimal Premiums

(Net of Lost Driving Benefits)

Gas Elasticity 0.15

\begin{tabular}{|c|c|c|c|c|c|c|}
\hline \multirow[t]{2}{*}{ Model } & \multicolumn{2}{|c|}{$\begin{array}{c}A=c_{1} M \\
\text { Linear Model }\end{array}$} & \multicolumn{2}{|c|}{$\begin{array}{c}A=c_{1} M+c_{2} M^{2} / L \\
\text { Calibration Model }\end{array}$} & \multicolumn{2}{|c|}{$\begin{array}{c}A=c_{1} M+c_{2} M^{2} / L \\
\text { Regression model }\end{array}$} \\
\hline & $\begin{array}{c}\text { total } \\
\text { (dollars in millions) }\end{array}$ & $\begin{array}{c}\text { per insured vehicle } \\
\$\end{array}$ & $\begin{array}{c}\text { total } \\
\text { (dollars in millions) }\end{array}$ & $\begin{array}{c}\text { per insured vehicle } \\
\$\end{array}$ & $\begin{array}{c}\text { total } \\
\text { (dollars in millions) }\end{array}$ & $\begin{array}{c}\text { per insured vehicle } \\
\$\end{array}$ \\
\hline Alabama & 36 & 14 & 109 & 42 & 67 & 26 \\
\hline Alaska & 13 & 38 & 32 & 96 & 19 & 58 \\
\hline Arizona & 93 & 33 & 269 & 95 & 178 & 63 \\
\hline Arkansas & 31 & 16 & 83 & 45 & 49 & 26 \\
\hline California & 548 & 34 & 1719 & 106 & 1305 & 80 \\
\hline Colorado & 91 & 34 & 244 & 90 & 150 & 55 \\
\hline Connecticut & 138 & 59 & 396 & 170 & 301 & 129 \\
\hline Delaware & 22 & 43 & 66 & 129 & 49 & 96 \\
\hline Florida & 306 & 36 & 918 & 108 & 659 & 78 \\
\hline Georgia & 112 & 21 & 338 & 64 & 223 & 42 \\
\hline Hawaii & 57 & 81 & 159 & 226 & 129 & 183 \\
\hline Idaho & 8 & 11 & 21 & 27 & 12 & 15 \\
\hline Illinois & 205 & 27 & 593 & 79 & 390 & 52 \\
\hline Indiana & 75 & 18 & 228 & 55 & 148 & 36 \\
\hline lowa & 29 & 13 & 72 & 33 & 42 & 19 \\
\hline Kansas & 32 & 15 & 75 & 35 & 43 & 20 \\
\hline Kentucky & 58 & 21 & 169 & 61 & 106 & 38 \\
\hline Louisiana & 96 & 39 & 272 & 110 & 177 & 72 \\
\hline Maine & 14 & 15 & 42 & 45 & 26 & 28 \\
\hline Maryland & 127 & 38 & 384 & 114 & 292 & 87 \\
\hline Massachusetts & 263 & 66 & 749 & 187 & 585 & 146 \\
\hline Michigan & 237 & 33 & 676 & 94 & 452 & 63 \\
\hline Minnesota & 85 & 26 & 224 & 68 & 133 & 41 \\
\hline Mississippi & 21 & 15 & 61 & 42 & 36 & 24 \\
\hline Missouri & 69 & 19 & 199 & 54 & 122 & 33 \\
\hline Montana & 8 & 11 & 16 & 25 & 10 & 15 \\
\hline Nebraska & 18 & 13 & 41 & 30 & 24 & 18 \\
\hline Nevada & 39 & 39 & 100 & 99 & 60 & 59 \\
\hline New Hampshire & 24 & 28 & 71 & 82 & 47 & 54 \\
\hline New Jersey & 453 & 86 & 1241 & 236 & 991 & 189 \\
\hline New Mexico & 21 & 19 & 58 & 52 & 34 & 30 \\
\hline New York & 574 & 60 & 1604 & 167 & 1162 & 121 \\
\hline North Carolina & 114 & 19 & 344 & 59 & 229 & 39 \\
\hline North Dakota & 4 & 7 & 6 & 14 & 4 & 9 \\
\hline Ohio & 165 & 21 & 501 & 63 & 341 & 43 \\
\hline Oklahoma & 35 & 15 & 95 & 40 & 55 & 23 \\
\hline Oregon & 52 & 22 & 139 & 60 & 83 & 36 \\
\hline Pennsylvania & 317 & 38 & 900 & 108 & 616 & 74 \\
\hline Rhode Island & 44 & 68 & 121 & 188 & 90 & 140 \\
\hline South Carolina & 63 & 23 & 182 & 67 & 116 & 43 \\
\hline South Dakota & 6 & 10 & 11 & 20 & 7 & 12 \\
\hline Tennessee & 55 & 16 & 166 & 47 & 106 & 30 \\
\hline Texas & 230 & 24 & 678 & 72 & 429 & 45 \\
\hline Utah & 23 & 18 & 66 & 52 & 40 & 31 \\
\hline Vermont & 8 & 17 & 22 & 49 & 13 & 29 \\
\hline Virginia & 105 & 21 & 325 & 66 & 226 & 46 \\
\hline Washington & 90 & 27 & 261 & 77 & 168 & 50 \\
\hline West Virginia & 37 & 29 & 103 & 81 & 64 & 50 \\
\hline Wisconsin & 56 & 15 & 161 & 44 & 97 & 27 \\
\hline Wyoming & 3 & 8 & 7 & 19 & 4 & 10 \\
\hline $\begin{array}{l}\text { U.S. Total } \\
\text { (disaggregated sum) }\end{array}$ & 5310 & 31 & 15319 & 91 & 10707 & 63 \\
\hline $\begin{array}{l}\text { National Model } \\
\text { (aggregated) }\end{array}$ & 4936 & 29 & 14174 & 84 & 9131 & 54 \\
\hline
\end{tabular}




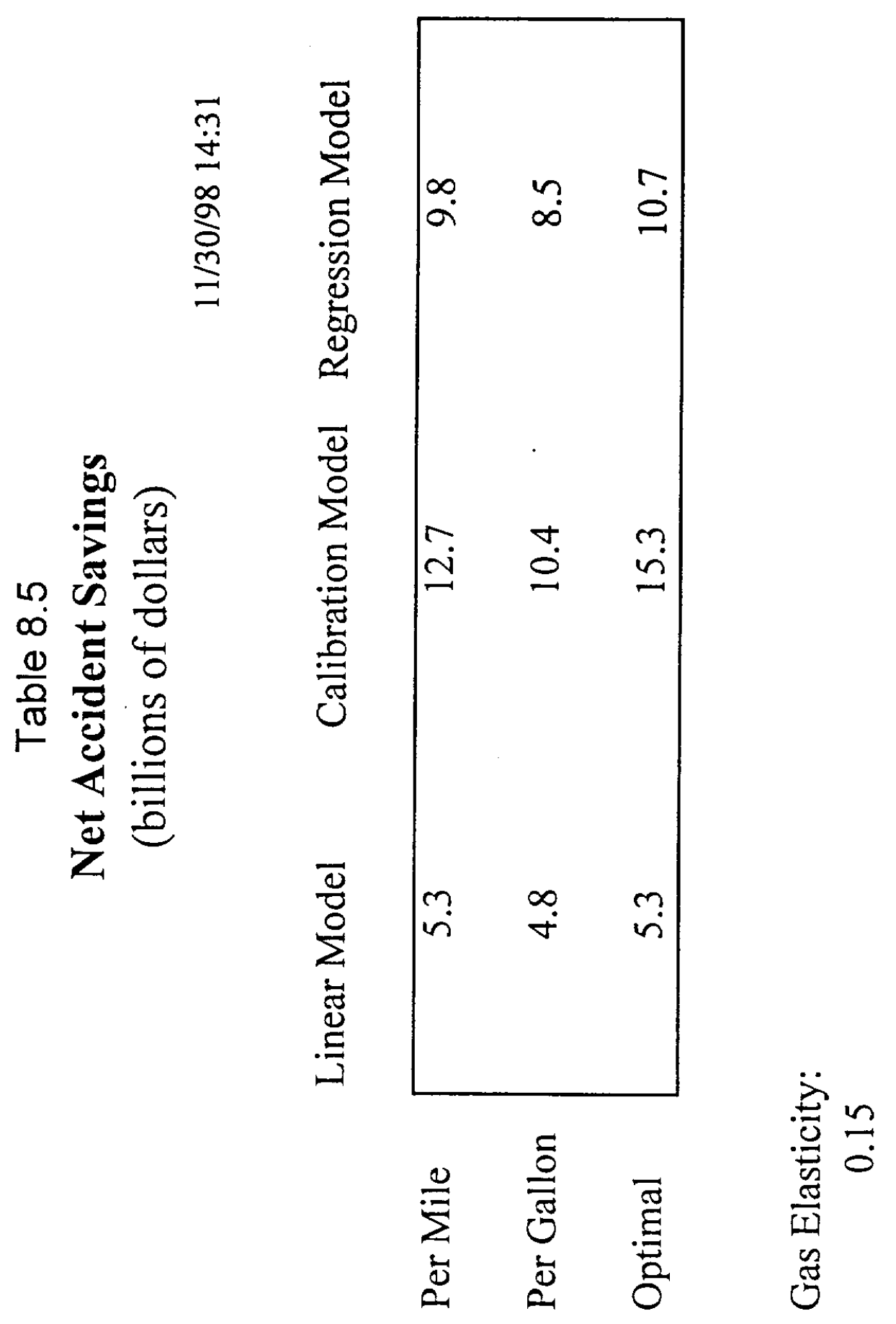




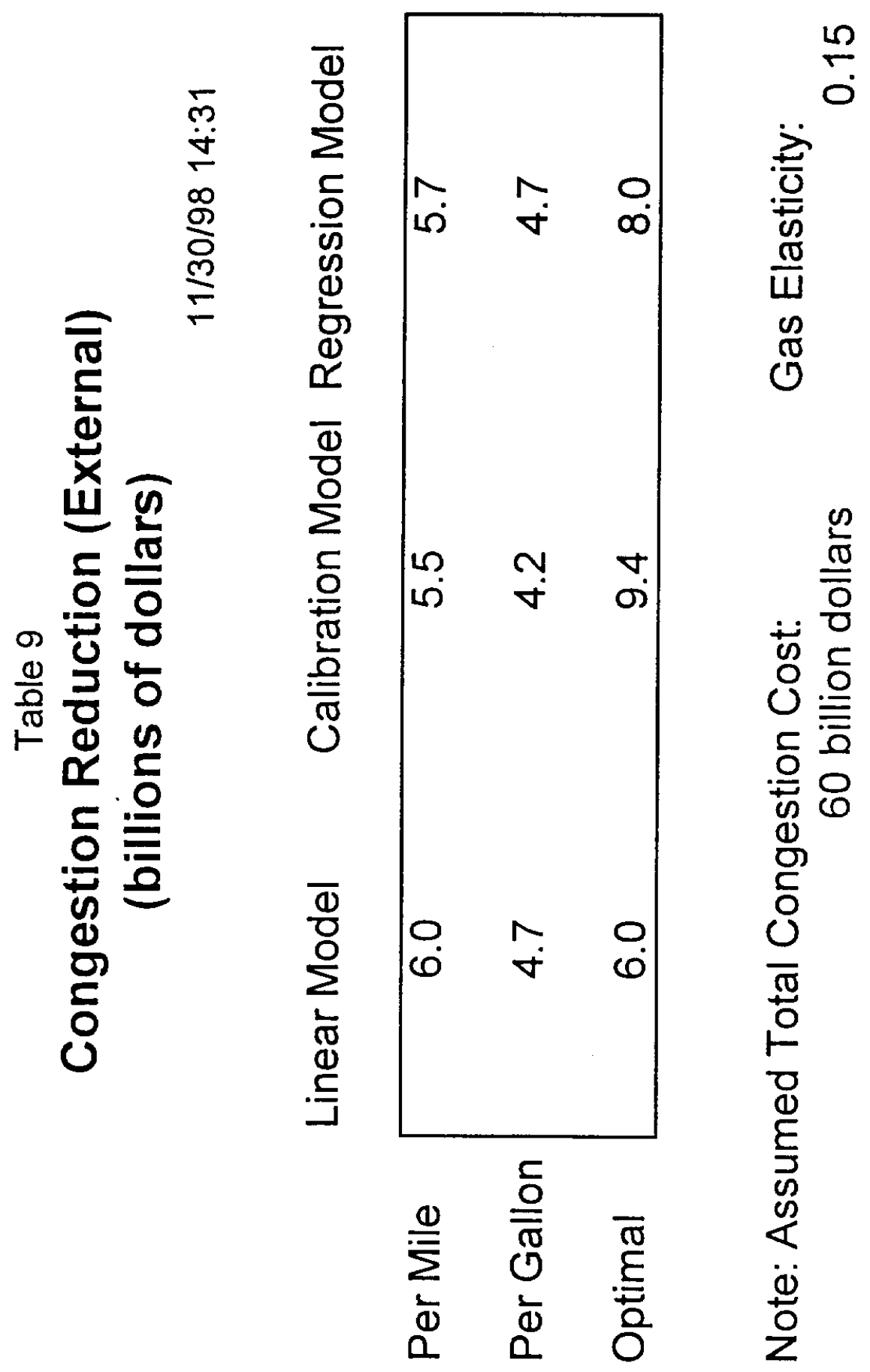




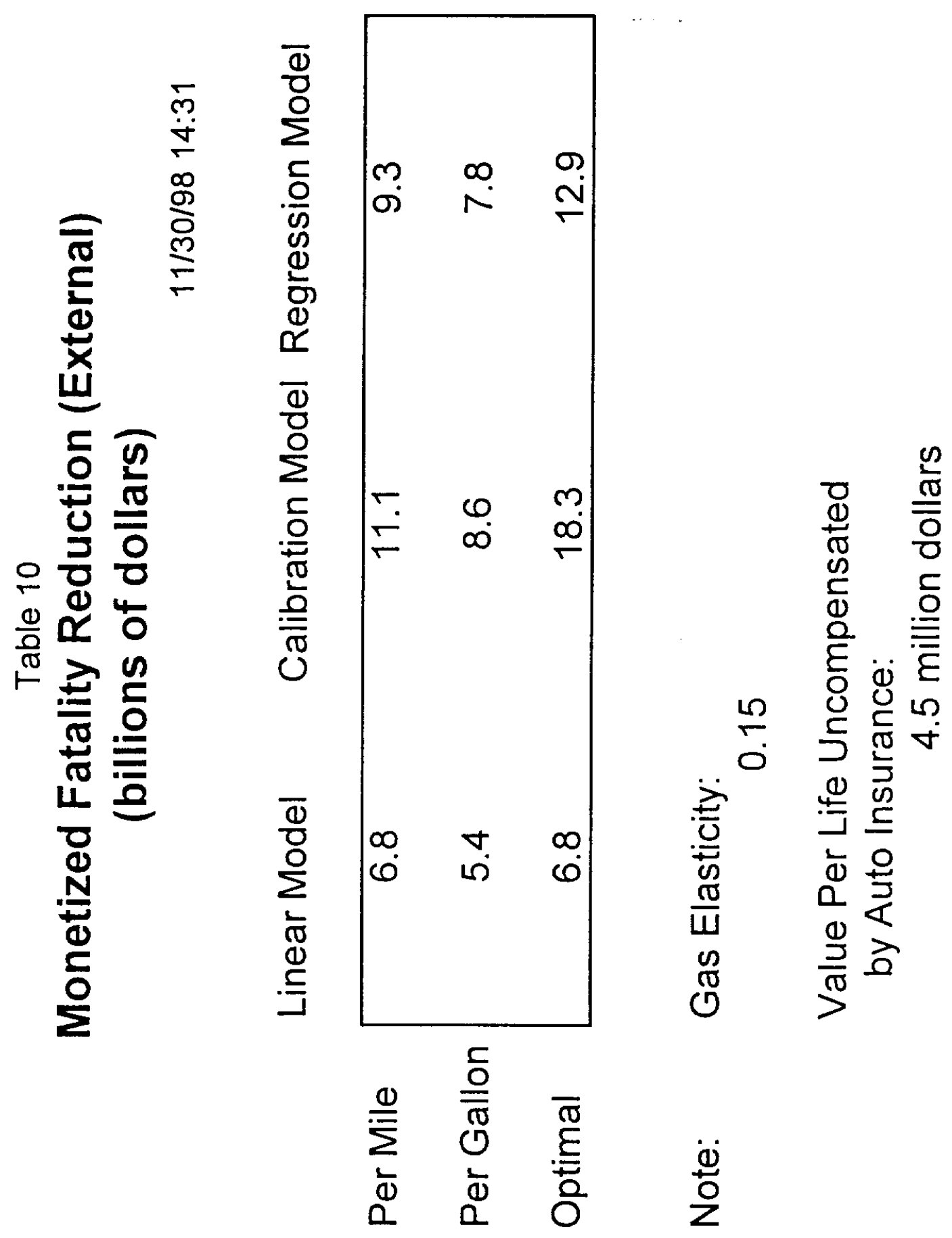




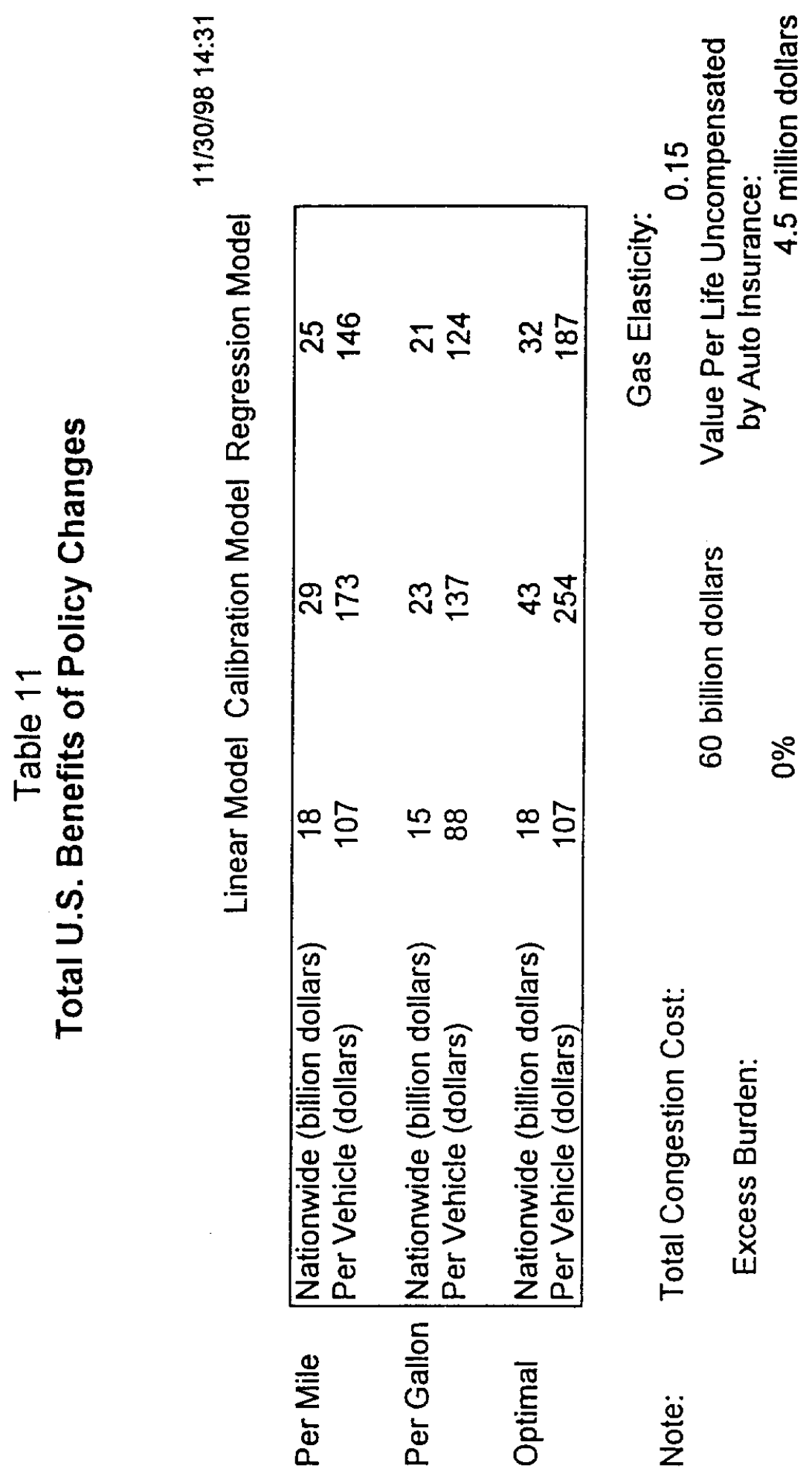

